\title{
QUEEN'S
UNIVERSITY
BELFAST
}

\section{High performance multiscale glass fibre epoxy composites integrated with cellulose nanocrystals for advanced structural applications}

Kumar, S., Falzon, B., Graninger, G., Hawkins, S., Kun, J., \& Wilson, E. (2020). High performance multiscale glass fibre epoxy composites integrated with cellulose nanocrystals for advanced structural applications. Composites Part A: Applied Science and Manufacturing, 131, [105801]. https://doi.org/10.1016/j.compositesa.2020.105801

Published in:

Composites Part A: Applied Science and Manufacturing

Document Version:

Peer reviewed version

Queen's University Belfast - Research Portal:

Link to publication record in Queen's University Belfast Research Portal

Publisher rights

Copyright 2020 Elsevier.

This manuscript is distributed under a Creative Commons Attribution-NonCommercial-NoDerivs License

(https://creativecommons.org/licenses/by-nc-nd/4.0/), which permits distribution and reproduction for non-commercial purposes, provided the author and source are cited.

\section{General rights}

Copyright for the publications made accessible via the Queen's University Belfast Research Portal is retained by the author(s) and / or other copyright owners and it is a condition of accessing these publications that users recognise and abide by the legal requirements associated with these rights.

Take down policy

The Research Portal is Queen's institutional repository that provides access to Queen's research output. Every effort has been made to ensure that content in the Research Portal does not infringe any person's rights, or applicable UK laws. If you discover content in the Research Portal that you believe breaches copyright or violates any law, please contact openaccess@qub.ac.uk. 


\section{Journal Pre-proofs}

High Performance Multiscale Glass Fibre Epoxy Composites Integrated with Cellulose Nanocrystals for Advanced Structural Applications

Sandeep Kumar, Brian G. Falzon, Jeffery Kun, Emma Wilson, Georg Graninger, Stephen C. Hawkins

PII: S1359-835X(20)30039-7

DOI: https://doi.org/10.1016/j.compositesa.2020.105801

Reference: JCOMA 105801

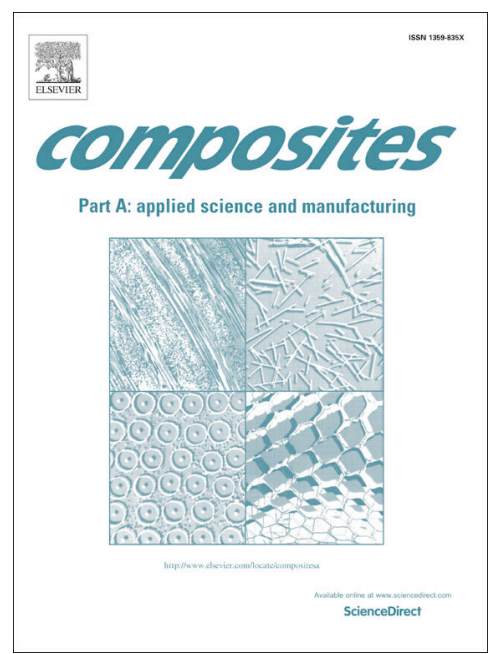

To appear in:

$$
\text { Composites: Part A }
$$

Received Date:

29 July 2019

Revised Date:

22 January 2020

Accepted Date:

25 January 2020

Please cite this article as: Kumar, S., Falzon, B.G., Kun, J., Wilson, E., Graninger, G., Hawkins, S.C., High Performance Multiscale Glass Fibre Epoxy Composites Integrated with Cellulose Nanocrystals for Advanced Structural Applications, Composites: Part A (2020), doi: https://doi.org/10.1016/j.compositesa.2020.105801

This is a PDF file of an article that has undergone enhancements after acceptance, such as the addition of a cover page and metadata, and formatting for readability, but it is not yet the definitive version of record. This version will undergo additional copyediting, typesetting and review before it is published in its final form, but we are providing this version to give early visibility of the article. Please note that, during the production process, errors may be discovered which could affect the content, and all legal disclaimers that apply to the journal pertain.

(C) 2020 Published by Elsevier Ltd. 
High Performance Multiscale Glass Fibre Epoxy Composites Integrated with Cellulose Nanocrystals for Advanced Structural Applications

Sandeep Kumar ${ }^{a^{*}}$, Brian G. Falzon ${ }^{\text {a*}}$, Jeffery Kun a , Emma Wilson ${ }^{\text {a }}$, Georg Graninger ${ }^{\mathrm{a}}$, Stephen C. Hawkins a,b

a School of Mechanical and Aerospace Engineering, Advanced Composite Research Group, Queen's University Belfast, Ashby Building, Belfast BT9 5AH, UK

${ }^{\mathrm{b}}$ Department of Materials Science and Engineering, Monash University, Clayton, Victoria 3800, Australia

Email: b.falzon@qub.ac.uk

Sandeep.Kumar@qub.ac.uk

\begin{abstract}
:
Recently, considerable effort has been devoted to develop cellulose nanocrystal(CNC)/epoxy (EP) composites with improved properties. However, work on CNC-enhanced continuous fibre reinforced polymer (FRP) composites has received little attention. In this study, a $\mathrm{CNC/epoxy}$ mixture was infused through plain-woven glass fabric (GF) reinforcement to develop hierarchical CNC/GFRP composites. The results show that CNC/GFRP composites exhibit significantly enhanced mechanical properties compared to the GFRP control composite. The addition of $2 \mathrm{wt} \% \mathrm{CNC}$ to GFRP yielded increases of $56 \%$ in storage modulus, $50 \%$ in flexural modulus, $55 \%$ in flexural strength, $14 \%$ in tensile modulus and $24 \%$ in tensile strength. Morphological studies (SEM) confirm the strong anchoring of CNCs with GF and the EP interphase thin layer around the GF. These results show that CNCs can be effective for strengthening the interface in fibre-reinforced composites for structural applications.
\end{abstract}


Keywords: Polymer Matrix Composites; Cellulose nanocrystals; Rheological Properties; Mechanical Testing; Vaccum infusion

\section{Introduction}

Fibre reinforced polymer (FRP) composites possess excellent in-plane specific strength and stiffness, corrosion and fatigue resistance [1-2]. FRPs are now replacing metallic components in aerospace, automotive and marine industries; a weight reduction of 10 percent, in an automotive vehicle can lead to an increase in fuel economy of between 6 to 8 percent, and even higher efficiencies in aircraft [3-4]. These potential benefits are likely to see FRP composites being increasingly utilised in future transportation structures, as the sector seeks to minimise environmental impact and reduce the use of fossil fuels through electrification.

Glass fibre reinforced polymer (GFRP) is sometimes selected for structural applications to meet specific requirements, where the use of higher-performing carbon fibres is neither warranted nor economically viable [5]. Despite their attractive in-plane mechanical properties, the full potential of GFRP composites in structures is hindered by poor out-ofplane mechanical performance, mostly due to weak glass fibre-epoxy polymer matrix interfacial adhesion. Significant property enhancement can be achieved in GFRP composite, especially for the fibre-matrix interphase and out-of-plane/through thickness properties, by adding a small amount of a nanoscale reinforcement [6-7]. To date, extensive research on integrating carbon nanotubes (CNT)/graphene into various FRP composites has been reported [8-9]. Yuchang et al. reported the effect of graphene on the mechanical properties of glass fibre reinforced polymer (GFRP) epoxy composites. The flexural strength and modulus increased by up to $78 \%$ and $58 \%$ respectively at $2.0 \mathrm{wt} \%$ graphene compared to a control [10]. Rathore et al. also investigated CNT-embedded woven GFRP composites, reporting a 
$32 \%$ increase in flexural strength and an $11.5 \%$ increase in flexural modulus compared with GFRP alone, which they attributed to improved interfacial interactions and mechanical interlocking [11]. Although carbon nanomaterials have huge potential, acceptance is hampered by the high cost of good quality CNT and Graphene [12-13].

Cellulose nanocrystals (CNC), as a preferable alternative to $\mathrm{CNT} /$ graphene, with an exceptional sustainability profile, have recently received much attention owing to their outstanding intrinsic properties such as axial stiffness of 100-143 GPa and high tensile strength $(\sim 10 \mathrm{GPa})[14-15]$. They can be obtained with a range of aspect ratios, depending upon the source, e.g. cotton, wood, wheat straw, corn cob or tunicate (length of $150 \mathrm{~nm}$ to a few microns and length/diameter $\sim 10-80$ ). Very little work on the use of CNC to enhance the mechanical properties of FRP composites has been reported [16-18]. Gabr et al. mixed 0.5 $\mathrm{wt} \%$ crystalline bacterial cellulose $(\mathrm{BC})$ in ethanol with rubber-modified epoxy to manufacture carbon fibre/BC composites with mode I initiation and propagation interlaminar fracture toughness improved by $84 \%$ and $72 \%$ respectively, although with only moderate improvement in storage modulus and tensile properties [16]. However, solvent use places limitations on industrial implementation and the hand layup used is inappropriate for scalability. Recently, Asadi et al. showed that $0.9 \mathrm{wt} \% \mathrm{CNC}$ in short-GF epoxy sheet moulding compound (SMC) increased tensile modulus by $25 \%$, tensile strength by $30 \%$ and tensile strain at break by $22 \%[17-18]$.

Continuous long fibre reinforcements are preferable to discontinuous short/chopped fibre reinforcements to achieve effective strengthening and stiffening in highly loaded composite structures. We now report work on CNC-enhancement of GFRP polymer composites 
manufactured using a vacuum-assisted resin infusion process. This method is currently the most widely used process to manufacture large volume medium/high-performance structural FRP composite parts.

\section{Experimental}

\subsection{Materials}

A two-component ultra-low viscosity $\left(\eta \sim 500 \mathrm{mPa} . \mathrm{s}\right.$, density $\left.\sim 1.12 \mathrm{~g} / \mathrm{cm}^{3}\right)$ infusion-grade epoxy resin, based on a diglycidyl ether of bisphenol A (DGEBA) and poly(oxypropylene) diamine (slow hardener AT30, $\eta=10-20 \mathrm{mPa} . \mathrm{s}$, density $1.10 \mathrm{~g} / \mathrm{cm}^{3}$ ) was mixed and cured according to the supplier's recommendation (resin: hardener (100:30), $\uparrow \sim 200 \mathrm{mPa}$.s, density $1.12 \mathrm{~g} / \mathrm{cm}^{3}$, pot life $90 \mathrm{~min}$.). Resin and consumables (release agent and mould cleaner, Easy Lease $^{\mathrm{TM}}$ ), vacuum bagging film (Green translucent $100 \%$ nylon, VB200), gum sealant, spiral tubing (4.5mm OD), resin infusion mesh (polypropylene FM100), silicon connectors, catch pot, and aero-grade nylon 66 peel ply (PP230) were supplied by Easy Composites Ltd., U.K. Plain woven E-glass fibre fabric reinforcement (RE50 P, density $2.50 \mathrm{~g} / \mathrm{cm}^{3}$, modulus 69 $\mathrm{GPa}$, tensile strength $2.4 \mathrm{GPa}$ and fibre diameter $5.0-5.5 \mu \mathrm{m}$ ) was supplied by Gurit (UK) Ltd. Cellulose nanocrystals were supplied by Cellulose Lab, Canada, as a freeze-dried powder. As assessed by two microscopic techniques (scanning electron microscopy (SEM); JEOL JSM6500 and atomic force microscopy (AFM); Cypher ${ }^{\mathrm{TM}}$ Asylum), CNCs have elongated needle-like shape morphology with average individual crystal width $23 \pm 4.4 \mathrm{~nm}$ and length $296 \pm 78 \mathrm{~nm}$ measured from SEM images. In comparison, AFM height profile also confirmed average width in the same range $22 \pm 5 \mathrm{~nm}$. Fig. S1 shows the chemical structures of all the materials used (Supplementary information, Fig S1). 


\subsection{Epoxy (EP)/Cellulose nanocrystals (CNC) mixtures}

The typical procedure for the preparation of $\mathrm{EP} / 0.5 \mathrm{wt} \% \mathrm{CNC}$ composite mixtures was to mechanically stir $105 \mathrm{~g}$ of EP monomer and $0.7 \mathrm{~g}$ of $\mathrm{CNC}$ powder in a beaker under ambient conditions using IKA Eurostar 40 mixer (turbine blade $30 \mathrm{~mm}$ dia.) overnight at $2000 \mathrm{rpm}$ followed by high shear mixing (T25 UltraTurrax ${ }^{\circledR}$ IKA, stator diameter: $18 \mathrm{~mm}$ ), at 25,000 rpm for $2 \mathrm{~min}$ and $10,000 \mathrm{rpm}$ for $8 \mathrm{~min}$. Finally, the mixture was probe sonicated for 2-3 min (using Soniprep 150, tapered tip dia. 3mm and amplitude 15 microns) and during sonication the temperature was maintained below $50^{\circ} \mathrm{C}$. After cooling the mixture to $20^{\circ} \mathrm{C}$, hardener $(31.5 \mathrm{~g})$ was added and mixed for 2-3 mins at $500 \mathrm{rpm}$ followed by degassing prior to use. Pure EP samples and CNC/EP with CNC loadings of $0.5 \mathrm{wt} \%$ to $10 \mathrm{wt} \%$ were prepared using the same mixing process and found to be stable to sedimentation or aggregation. Fig. S2 (supplementary information) shows the schematic representation of the preparation of $\mathrm{CNC} / \mathrm{EP}$ nanocomposites and digital images of $\mathrm{CNC}$ and $\mathrm{CNC} / \mathrm{EP}$ nanocomposites. It should be remarked that the processing conditions and CNC loadings were derived at after several trials of mixing conditions and dispersion studies.

\subsection{CNC/GFRP composite preparation}

Resin dispersions of $0.5 \mathrm{wt} \%$ and $2.0 \mathrm{wt} \% \mathrm{CNC}$ were used for CNC/GFRP composite sample preparation. The plain-woven GF fabric was cut into $260 \mathrm{~mm}$ x $150 \mathrm{~mm}$ samples and dried at $150^{\circ} \mathrm{C}$ overnight. Each layup consisted of twenty-five layers of fabric, which were stacked on a cleaned flat aluminium tool, vacuum bagged and resin infused under full vacuum (Fig.2 and supplementary material). Curing was performed at room temperature for about $24 \mathrm{~h}$ and then post cured at $70^{\circ} \mathrm{C}$ for $6 \mathrm{~h}$. Cured composite laminates were cut to size by wet diamond saw (VITREX versatile pro 750) (Supplementary information, Fig.S3). 
The fibre volume fraction (FVF) for the composite laminates was estimated by the density method according to Eq 1,

$$
V_{f}=\left(\rho_{c}-\rho_{m}\right) /\left(\rho_{f}-\rho_{m}\right)
$$

where $\rho_{c}, \rho_{m}$ and $\rho_{f}$ are the density of the composite, matrix and fibre, respectively [19]. The average measured density of the composite was $1.67 \mathrm{~g} / \mathrm{cm}^{3}$. The density of the matrix and fibre was $1.12 \mathrm{~g} / \mathrm{cm}^{3}$ and $2.5 \mathrm{~g} / \mathrm{cm}^{3}$ respectively. The average FVF was estimated to be $\sim 39 \pm 0.01 \mathrm{vol} \%$. Composite laminate specifications are provided in Table $1 \mathrm{~S}$ (supplementary information)

\section{Characterization}

The size, shape, morphology and dispersion/infiltration of $\mathrm{CNC}$ in the laminates was analysed by SEM and AFM. The vacuum and accelerating voltage was in the order of $10^{-4}$ to $10^{-6} \mathrm{mmHg}$ and $5-10 \mathrm{kV}$ during scanning of the composite samples. In AFM, AM-FM viscoelastic mapping mode was used to capture the local interface modulus at fibre/matrix interface for GFRP and CNC/GFRP composite samples. In this mode, the cantilever frequency/amplitude respond sensitively to changes in the sample properties during scanning. The cantilever high frequency response means high stiffness/modulus. For contact stiffness measurements with AM-FM Mode, we used an AC 160 TSA probe with cantilever spring constant $38.5 \mathrm{~N} / \mathrm{m}$ accurately calibrated with GetReal ${ }^{\mathrm{TM}}$ software. Tensile and flexural (three point bending) properties of $\mathrm{CNC} / \mathrm{EP}$ nanocomposites were obtained using a Zwick/Roell Z100 testing machine. The tensile tests were performed as per the ASTM D638 standard. Flexural tests were conducted using a three-point bending rig (load cell capacity: $10 \mathrm{kN}$, ASTM D 790) [2]. Samples with planar dimensions $250 \mathrm{~mm}$ x $25 \mathrm{~mm}$ (for tensile testing) and $70 \mathrm{~mm} \times 12 \mathrm{~mm}$ (for flexural testing) were cut from the composite laminate panels 
(average thickness $1.38 \mathrm{~mm}$ ). The flexural modulus of elasticity was calculated from the linear portion of the stress-strain curves between $0.05 \%$ and $0.25 \%$ strain. All tests were carried out at room temperature, with five specimens tested for each composition. The oscillatory and steady-state rheological properties of uncured $\mathrm{CNC} / \mathrm{EP}$ mixtures were measured using a TA AR2000 rheometer with narrow gap concentric cylindrical geometry. Steady-state experiments were done over a shear rate range of 0.1 to $1000 s-1$ and frequency sweeps were performed in a frequency range of 0.01 to $100 \mathrm{rad} / \mathrm{s}$ at constant strain of $0.05 \%$. Strain sweep tests were performed between $0.01 \%$ and $1 \%$ to guarantee the oscillatory experiments conducted within the linear viscoelastic regime. Attenuated total reflectionFourier transform infrared (ATR-FTIR) spectra of CNC, EP monomer and cured CNC/EP were recorded on a Perkin Elmer Spectrum 100 FTIR spectrometer. X-ray diffraction (XRD) of CNCs was carried out using PANalytical X-ray diffractometer (Model: X' pert Pro) at a step size of $0.020^{\circ}$ in the $2 \theta$ range of $5-65^{\circ}$. Density of the composites was measured using water displacement using Sartorius weighing specific gravity kit as per ASTM standard D792 [3]. Dynamic mechanical thermal analysis (DMTA) was used to characterize the viscoelastic properties of the CNC/GFRP composites using a TA instrument Tritec DMA 2000 in the dual cantilever bending mode. The samples were subjected to a sinusoidal displacement of $0.05 \%$. The testing temperature was varied from $25^{\circ} \mathrm{C}$ up to $180^{\circ} \mathrm{C}$ at a constant test frequency of 1 $\mathrm{Hz}$ and heating rate of $3^{\circ} \mathrm{C} / \mathrm{min}$.

\section{Results and discussion}

In going from pure $\mathrm{EP}$ up to $2.0 \mathrm{wt} \%$ of $\mathrm{CNC}$ the mixtures exhibit only a slight increase in viscosity from 0.5 Pa.s to 1.1 Pa.s (Fig. 3a), most likely due to there being minimal CNCCNC interaction. The slight thinning with shear rate can be attributed to the orientation of the finely dispersed rigid CNCs. However, at $5.0 \mathrm{wt} \%$ and $10.0 \mathrm{wt} \% \mathrm{CNC}$, a sharp increase in viscosity and decreased shear response are observed (Fig. 3a). This behaviour can be 
attributed to the formation of three dimensional networks by CNCs with increasing content. At $10 \mathrm{wt} \% \mathrm{CNC}$, an inflection in the shear thinning at about $1 \mathrm{~s}^{-1}$ possibly reflects a transition from a 3D network to a non-interacting distribution of CNC particles. The behaviour of the $\mathrm{CNC} / \mathrm{EP}$ mixtures at $\leq 2 \mathrm{wt} \%$ is typical of a viscoelastic liquid as indicated by the storage modulus $\left(\mathrm{G}^{\prime}\right)$ in Fig. 3b. However, above $5.0 \mathrm{wt} \% \mathrm{CNC}$, behaviour changes from terminal to non-terminal at low frequency. At $10.0 \mathrm{wt} \%$ loading of $\mathrm{CNC}, \mathrm{G}^{\prime}$ varies only slightly with frequency at low values, indicating formation of a robust network of CNCs which hinders the movement of the matrix's macromolecular chains and provide resistance against applied deformation.

Tian et al. reported that a $\mathrm{CNC}-\mathrm{CNC}$ network starts to form around $3.0 \mathrm{wt} \%$, and this network grows stronger with increase in CNC concentration [20]. In comparison to CNCs, high aspect ratio fillers like cellulose nanofibrils (CNFs, 1/d 80) and CNTs (1/d 100-1000) produce a highly entangled network even below $1.0 \mathrm{wt} \%$ causing a drastic increase in viscosity that may be beyond the practically accepted limit for resin infusion $(>1.0 \mathrm{~Pa} \cdot \mathrm{s})[21-$ 22]. The highly viscous mixtures lead to poor and non-uniform impregnation of fibre assemblies. The recommended viscosity limit for the vacuum-assisted infusion process of high volume structural parts, such as wind turbine rotor blades and long boat hulls, is usually around $1.0 \mathrm{~Pa} \cdot \mathrm{s}[23]$. In the present case, the addition of $30 \% \mathrm{v} / \mathrm{v}$ liquid hardener $(\eta \sim 0.01$ $\mathrm{Pa} . \mathrm{s})$ to the $\mathrm{CNC} / \mathrm{EP}$ mixture expected to further reduce the viscosity to bring the $2.0 \mathrm{wt} \%$ $\mathrm{CNC} / \mathrm{EP}$ mixture into the infusion range.

The FTIR spectrum of CNCs (Fig. 3c) shows a broad band that can be deconvoluted to three peaks. These are attributable to intramolecular-hydrogen bonding between cellulose hydroxyl 
groups at $3427 \mathrm{~cm}^{-1}$, and to intermolecular H-bonding $\left(3325 \mathrm{~cm}^{-1}\right.$ and $\left.3270 \mathrm{~cm}^{-1}\right)$ as well as to the $\beta$ phase of cellulose [24]. The FTIR spectrum of processed uncured EP monomer (Fig. 3c) shows a small absorption peak centred at $3500 \mathrm{~cm}^{-1}$ attributable to free hydroxyl. The small $\mathrm{C}-\mathrm{H}$ stretching peak at $3057 \mathrm{~cm}^{-1}$ corresponds to the terminal oxirane ring of epoxy [25]. In the cured resin, the large peak centred at $3360 \mathrm{~cm}^{-1}$ corresponds to the hydroxyls from opening of the epoxide. In the cured EP, the cluster of peaks $2800-3000 \mathrm{~cm}^{-1}$ is generally ascribed to aliphatic alky stretching vibrations [24-25]. This is heavily augmented by the alkyl-H from the curing agent (PPA).

The pure cured EP resin exhibits a symmetric hydroxyl peak at about $3260 \mathrm{~cm}^{-1}$, and the addition of just $2.0 \mathrm{wt} \% \mathrm{CNC}$ makes only a small contribution to intensity of this band. However, for the cured $\mathrm{CNC} / \mathrm{EP}$, a strong and distinctive peak appears at $3406 \mathrm{~cm}^{-1}$ within the hydroxyl band (3500-3000 $\left.\mathrm{cm}^{-1}\right)$ which confirms the strong interaction between epoxidederived hydroxyl groups and those present on the surface of CNCs. This development indicates the strong hydrogen bonding interactions between CNC and EP matrix [26]. The small broad absorption peak at $3263 \mathrm{~cm}^{-1}$ is attributable to intermolecular bonding between hydroxyl group of CNCs and -N-H (amines) in adjacent molecular chains [27]. Disappearance of the peak at $913 \mathrm{~cm}^{-1}$ confirms that epoxide group completely reacted in cured $\mathrm{EP}$ and $\mathrm{CNC} / \mathrm{EP}$ (Fig.3d). The $\mathrm{C}-\mathrm{O}$ and $\mathrm{C}-\mathrm{O}-\mathrm{C}$ stretching band in $\mathrm{CNCs}$ at 1059 and $1110 \mathrm{~cm}^{-1}$ moved to high and lower frequencies in the cured $\mathrm{CNC} / \mathrm{EP}$, demonstrating that interactions are established between CNCs and EP matrix (through hydrogen bonding) [24]. The sharp peak observed at 1181 in the epoxy spectrum is attributed to the C-O-C linkage. The further broadening and noticeable decrease in peak intensity at $1181 \mathrm{~cm}^{-1}$ possibly indicates that the linkage between epoxy resins and hydroxyl groups of CNCs through 
hydrogen bonding. There are several reports, which support the strong interaction of CNC with EP via either hydrogen or covalent linkage [20, 25].

In order to verify the reinforcement effect of $\mathrm{CNC}$ on the mechanical performance of $\mathrm{CNC} / \mathrm{EP}$ nanocomposites, we performed tensile, flexural and dynamic analysis of the EP and $\mathrm{CNC} / \mathrm{EP}$ nanocomposites. Tensile results revealed that that $\mathrm{CNC}$ had a noticeable reinforcing effect on the tensile strength and modulus of $\mathrm{CNC} / \mathrm{EP}$ nanocomposites (Fig.4a). The increase in strength validates the presence of individual strongly bonded CNCs to EP molecular chains and therefore effective stress transfer from EP to CNCs. The highest tensile strength and Young's modulus achieved for the $\mathrm{CNC} / \mathrm{EP}$ was $79 \pm 1.5 \mathrm{MPa}$ and $3.2 \pm 0.05 \mathrm{GPa}$ at a loading of $2 \mathrm{wt} \%$, which shows a $16 \%$ and $18 \%$ increment over the control EP $(68 \pm 1.46 \mathrm{MPa}$ and $2.7 \pm 0.04 \mathrm{GPa}$ ). The flexural modulus increased from $2.5 \pm 0.04 \mathrm{GPa}$ to $3.3 \pm 0.035 \mathrm{GPa}$ (32\%) and strength from $95 \pm 2.2 \mathrm{MPa}$ to $115 \pm 3.0 \mathrm{MPa}(21 \%)$ at $2.0 \mathrm{wt} \%$ of CNC (Fig. 4 b). The large surface area, high rigidity of the added CNCs (100-143 GPa) as well as high stiffness of interface between CNCs-EP, can be considered critical to this significant enhancement. The storage modulus (E') enhancement also followed the consistent trend with increasing amount of $\mathrm{CNCs}$ as confirmed by dynamic mechanical analysis (Fig. 4c). The storage modulus in the glass state with $2.0 \mathrm{wt} \% \mathrm{CNC}$ increased by $32 \%$, but more pronounced improvements were observed in the rubbery state above $T_{g}\left(E^{\prime}\right.$ at $\left.120^{\circ} \mathrm{C}\right)$ by $44 \%$ at the same $\mathrm{CNC}$ content. The rubbery plateau generally considered as an indication of degree of interactions between matrix and filler. The improvements in mechanical properties are consistent with data reported in the literature [3, 14-15, 28].

To observe the quality of dispersion and interfacial interactions in CNC/EP nanocomposites, we performed a SEM study of the fractured surface of the control epoxy and $2.0 \mathrm{wt} \%$ 
CNC/EP nanocomposite. From low magnification SEM images Fig.5, it is quite evident that the morphology of the fractured surfaces is greatly affected by the addition of CNCs. The fractured surface of the control epoxy looks very smooth with riverlike patterns, normally caused by rapid crack propagation while CNC-filled epoxy nanocomposite shows highly corrugated rough surfaces. The high magnification SEM micrographs (Fig. 6 a \& b) clearly reveal the nanoscale dispersion of CNCs and suggest stronger bonding between CNCs and epoxy. The measured very small free space length between CNCs $\sim 268 \pm 141 \mathrm{~nm}$ (data obtained from more than 100 dispersed CNCs, Fig 6a) indicates faster diffusion of CNCs in the ultra-low viscosity epoxy resin using a combination of high shear mixing and ultrasonication. It can also be seen (Fig. 6c), that individual CNCs are interacting with the crack, and thus providing a strengthening mechanism. Breaking of CNCs and tethering of epoxy molecules over pulled -out CNCs confirm the strong interfacial interaction between CNC-EP matrix. Fig.7 shows X-ray diffraction spectra of control EP and its nanocomposites. The XRD pattern of cured EP exhibit a broad amorphous peak at $2 \theta=18.8^{\circ}$. Albeit, the spectra of CNC/EP exhibit a similar diffraction pattern, but for a tiny broad shoulder hump at $22.5^{\circ}$ observed for the $2.0 \% \mathrm{CNC}$ nanocomposite, corresponding to a sharp crystalline peak of CNC. This implies that CNCs were possibly well dispersed in epoxy and more importantly the parent crystal structure of cellulose I is well preserved in the nanocomposites [29]. In summary, the rheology, FTIR, mechanical properties, SEM and XRD studies provide evidence of interactions between CNCs and epoxy matrix.

$\mathrm{CNC} / \mathrm{EP}$ mixtures, generated by mixing the EP resin with CNCs, using slow AT30 as a curing agent, were used to fabricate CNC/GFRP composites to demonstrate the industrial application of CNCs to enhance the properties of GFRP. We selected 0.5 and $2.0 \mathrm{wt} \%$ of CNC loading on the basis of rheological studies of CNC/EP to below $<5.0 \mathrm{wt} \%$. 
To analyse the reinforcement efficiency of $\mathrm{CNCs}$, tensile, flexural and dynamic mechanical analysis of CNC/GFRP composites was performed. Fig. 8 shows the tensile stress-strain curves of GFRP and CNC/GFRP composites. The experimental results obtained from the stress-strain curves are tabulated in Table 1. Tensile strength $\left(\sigma_{\mathrm{ts}}\right)$, young's modulus $(\mathrm{E})$ and failure strain $(\varepsilon \%)$ are significantly enhanced with the incorporation of CNCs (Fig.8). The GFRP composite with $2.0 \mathrm{wt} \% \mathrm{CNC}$ yields $\sigma_{\mathrm{ts}}=332 \pm 9.2 \mathrm{MPa}, \mathrm{E}=11.7 \pm 0.26 \mathrm{GPa}$ and $\varepsilon \%=4.2 \pm 0.10$ which are $24 \%, 14 \%$ and $13 \%$ higher, respectively, compared to control GFRP samples (the measured properties of control samples are comparable to values reported in the literature by other research groups) $[2,7,9,30]$. The improvements in tensile strength can be attributed to the improved interfacial strength between glass fibres and matrix through functional nanofillers (as shown in SEM morphological studies discussed later). The improved interface adhesion facilitates better load transfer from the matrix to the fibres and thus allowing the $\mathrm{CNC} / \mathrm{GFRP}$ composite to bear a higher load [17-18]. The improvement in the tensile modulus of CNC/GFRP could be due to the increase in modulus of the EP matrix by $\mathrm{CNC}$ (as shown in Fig.4a). It has also been suggested that stiffening of the local interface region (GF/EP) also contributes to this observed increase in modulus [31-32]. To gain deeper insight into the fibre/matrix interface, we have incorporated AM-FM viscoelastic mapping of polished GFRP and CNC/GFRP cross-sections to explore the interfacial properties of matrix and reinforcement (Fig. 9). In the case of the GFRP composite, the modulus transition is quite abrupt from matrix to fibre (interface thickness $\sim 49 \mathrm{~nm}$ ) due to greater difference in the modulus between fibre and interface layer, which is generally ascribed to the poor interfacial adhesion. However, for the GFRP/CNC composite, the interphase thickness increased to 235 $\mathrm{nm}$ with distinct modulus transition. The larger interfacial regions suggest a modification of the fibre/epoxy interface by CNCs. It is postulated that the larger interface is a factor in strengthening the GFRP/CNC interface [6]. 
We also performed flexural (Fig.10) and dynamic mechanical thermal analysis (Fig.11) of composites in bending mode. It is well known that in bending, fibre/matrix interfacial strength is very crucial to interlaminar crack propagation and buckling/delamination of fibre/matrix interface. The flexural strength and modulus increased by $55 \%$ and $50 \%$, respectively, compared to GFRP composite, when $2.0 \mathrm{wt} \% \mathrm{CNC}$ was added (Fig. 10). It is important to note that improvement in flexural performance is quite considerable compared to the tensile performance at the same CNC content. There are many reports available in the scientific literature with a similar kind of trend [18, 31-34]. Although, the tensile and flexural performances depend on the intrinsic stiffness/modulus of individual constituents, flexural strength is very sensitive to the fibre/matrix interface. Strong interface support the reinforcing fibres against buckling and delamination. In CNC/GFRP composites, high flexural strength is obtained via good dispersion in terms of homogeneity, and separation of individual CNCs within the epoxy surrounding the fibre surface which offers an interface strengthening mechanism by bridging/supressing the surface microcracks. The "crack-tip bridging" effect facilitates redistribution of the stresses around the surface cracks when CNCs homogenously dispersed in the interfacial regions, thereby delaying the crack opening. These bridging/crack healing effects suppress the localised interlaminar delamination and reduced the interlaminar stress concentration between the neighbouring layers, thus providing improved interlaminar adhesion that governs the flexural strength. Uniform dispersion of nanofillers reported to be very critical to the interfacial strength, the aggregation of nanoparticles in the matrix or interfacial area leads to stress concentration that reduces the strength of interface [35-37]. Another potential chemical interaction mechanism that possibly contribute to better interlaminar adhesion likely the presence of hydroxyl groups on the surface of CNC which can interact with GF via hydrogen bonding and open the epoxy epoxide ring to form covalent 
bonding $[18,31,38]$. Surprisingly, CNC/GFRP composites showed significant enhancement in the flexural modulus while tensile modulus is affected to a lesser extent. Several other studies have recorded similar discrepancies in the flexural and tensile moduli. For example, Patterson et al. observed a $68 \%$ increase in flexural modulus of the CFRP composites while tensile modulus was not affected at $2.0 \mathrm{wt} \%$ of aramid nanofiber (ANF) [33]. Asadi et al. investigated the $\mathrm{CNC} /$ short $\mathrm{GF} /$ epoxy composites and observed $25 \%$ increase in the tensile modulus and $44 \%$ increase in the flexural modulus at $0.9 \mathrm{wt} \% \mathrm{CNC}$ [17]. Jia et al. observed $23 \%$ and $53 \%$ increase in the tensile and flexural moduli for clay reinforced GFRP composites at $5.0 \mathrm{wt} \%$ clay [2]. In another work, Kim et al. developed CNT/CFRP composites and observed $11 \%$ increase in the flexural modulus with no change in the tensile modulus at $0.3 \mathrm{wt} \%$ CNTs [32]. According to these studies, while the tensile modulus is fibre dominated, flexural properties are matrix dominated. The significant improvement in the flexural modulus is attributed to the reinforcing effect of $\mathrm{CNC}$ in the matrix, and increase in the interphase modulus of the CNC-epoxy/GF composites, as confirmed by AFM (Fig. $9 b)[32,33,6,17]$.

The storage modulus provides a measure of elastic response/energy absorption ability of materials. Compared to the GFRP composites, CNC/GFRP composites show remarkable enhancement in the storage modulus below and above $\mathrm{Tg}$. In the glassy state region, incorporation of $0.5,1.0$ and $2.0 \mathrm{wt} \% \mathrm{CNC}$, increased the storage modulus to $20(11 \%), 24$ $(33 \%)$ and $29(56 \%)$ GPa with respect to GFRP (18 GPa). Above $\mathrm{T}_{\mathrm{g}}$ (rubbery state), the storage modulus of $\mathrm{CNC} / \mathrm{GFRP}$ composites significantly increased to $3.4,4.1$ and $4.4 \mathrm{GPa}$ with $0.5,1.0$ and $2.0 \mathrm{wt} \%$ of CNCs compared to GFRP (2.1 GPa). This remarkable jump in storage modulus, below and above $\mathrm{Tg}$, is attributed to uniform dispersion of CNCs in the epoxy matrix and the synergistic effect of strong chemical bonding and strong interlocking at the GFRP interface. Notably, the dynamic mechanical properties of the GFRP composites 
shows higher values compared to flexural and young's modulus. We postulate that, as reported by other researchers [39-42], the high storage modulus values are determined at very low strain and at high loading rate in a DMA compared to quasi-static testing. In addition, several studies have reported that the storage modulus is strongly related to the crosslink density of the matrix and fibre/matrix interface adhesion [31, 43]. In this respect, the presence of CNCs in the matrix as well as at the interface, seems to effectively contribute to restricting the motion of tightly packed polymer chains near the CNCs and at the fibre/matrix interface thus resulting in considerable increase in storage modulus of CNC/GFRP composite laminates.

Moreover, the addition of $2.0 \mathrm{wt} \% \mathrm{CNCs}$ to GFRP composites increased the $\mathrm{T}_{\mathrm{g}}$ to $100^{\circ} \mathrm{C}$ from $91.2^{\circ} \mathrm{C}$ for GFRP composites. The decrease of the height of the $\tan \delta$ peak of the CNC/GFRP is also observed. This can be possibly because of two main reasons (1) strong interaction between $-\mathrm{OH}$ functional groups present at the surface of $\mathrm{CNCs}$ and epoxy matrix that imposes restriction on the segmental motion of epoxy molecular chains (2) improvement of interfacial adhesion between EP matrix and GF due to the presence of CNC [34, 44-45]. Table 2 presents the comparative data of multiscale composites reinforced with a variety of nanofillers such as nanoclay, carbon nanotubes, graphene, graphene nanoplates etc. The purpose of this comparison is not to show the superiority of different filler reinforcements, but to show CNCs display overall robust improvements in thermo-mechanical properties at comparable filler loadings with the added advantage of being a bio-renewable and relatively low-cost filler. 
Morphological studies were performed to establish a structural property correlation and to observe the effect of CNCs on fracture morphology of GFRP composites. Compared to the GFRP composite, CNC/GFRP composites exhibit substantially different morphology. Fig.12 shows SEM images of a tensile fracture surface of GFRP and $2.0 \mathrm{wt} \% \mathrm{CNC} / \mathrm{GFRP}$ composite. Fig.12a shows interfacial debonding and fibre pull out. This confirms that mechanical failure happened due to weak interfacial adhesion between fibre and epoxy matrix. Whereas in $\mathrm{CNCs} / \mathrm{GFRP}$ composite (Fig.12b\&c), strong interfacial bonding between fibres and matrix is observed, and which is confirmed by equal straining of both fibres and matrix (concurrent failure). Fig.12c also shows the presence of tiny CNCs between fibres, which insure the uniform dispersion of CNCs without any aggregation. The white dotted particles represent the CNCs, as confirmed by other previous studies [15].

We also undertook the imaging of fibres transverse to the fracture direction to observe the mechanistic and fractographic features (Fig.13). The fracture surface of GFRP composite shows no sign of plastic deformation and the fibre surface is completely smooth (Fig.13a). The formation of cracks along the fibre direction indicates the weak interfacial adhesion. However, in CNC-enhanced GFRP composite (Fig. 13 b-d), the fibres are heavily coated uniformly with CNC-EP matrix even after the mechanical failure of the composite which is attributed to the strong interfacial interactions between fibre and matrix through CNCs. It is postulated that closely situated individualized CNCs (with a small gap of CNC-CNC $\sim 268 \pm 141 \mathrm{~nm}$ ) embedded within epoxy over fibres (as indicated by arrows, Fig 13c, magnified area from Fig.

13b (fibre surface)) offers an interface strengthening mechanism by bridging/supressing the microcracks. The fractograph (Fig. 14a) indicates that the CNCs in the interphase region (as indicated by a circle) act as an effective junction to influence the strengthening of the GFRP 
interface by keeping adjacent fibres and matrix intact. The SEM images, in Fig.14b, show the presence of highly oriented cusps which confirms extensive plastic deformation and progressive damage growth during tensile fracture. Interestingly, the high magnification SEM images (Fig. 15a-c) show that the needle like CNCs are strongly imbibed over the glass fibres and well adhered to the thin layer matrix over the fibres (Fig. $13 \mathrm{c}, 15 \mathrm{~b} \& \mathrm{c}$ ). It is assumed that the presence of $\mathrm{CNCs}$ in the fibre/epoxy interface region moves the reinforcing behaviour from microscopic level to nanoscale level, and these nanoscale CNCs may hinder the progression of cracks along and perpendicular to the GFRP interface thus contributing to the intra and interlaminar strengthening $[35,46]$. These synergistic chemical interfacial interactions elevated the energy absorption and therefore the corresponding composites exhibited higher strength and strain at failure.

A systematic scheme of proposed interaction mechanisms between $\mathrm{CNC}$, epoxy, and glass fibres is presented in Fig.S4 (see the supplementary information). Since the CNCs contain plenty of hydroxyl groups, it is likely that they can form hydrogen bonding with EP [20, 25]. However, covalent bonding through an etherification reaction between $-\mathrm{OH}$ of the $\mathrm{CNCs}$ and epoxy groups is also observed, as confirmed by the FTIR. The formation of new -OH (peak at $3406 \mathrm{~cm}^{-1}$ in FTIR of $\mathrm{CNC} / \mathrm{EP}$ ) groups indicates that CNCs reacted with the oxirane ring of EP. The newly formed -OH groups either can participate in the further cross-linking reaction with EP or can form hydrogen bonds with glass fibres and CNCs. Additionally, secondary/tertiary amines of cured EP can form hydrogen bonding with active - $\mathrm{OH}$ groups of CNCs [47]. The strong interfacial bonding between GFRP through CNCs, is therefore the result of heavily decorated surface $-\mathrm{OH}$ groups on CNCs interacting simultaneously with EP (through hydrogen/covalent) and forming $\mathrm{C}-\mathrm{O}-\mathrm{Si}$ bonding with glass fibres through a 
condensation reaction [48]. These simultaneous interface-strengthening interactions of CNC are well manifested through fractured morphologies.

\section{Conclusions}

This study demonstrates the strong reinforcement effect of CNCs in developing advanced hierarchical multiscale composites for industrial applications. To achieve this, $\mathrm{CNC} / \mathrm{EP}$ mixtures were generated by the combined action of high shear mixing and ultrasonication to fabricate $\mathrm{CNC} / \mathrm{GFRP}$ composites. Vacuum resin infusion was used for the fabrication of CNC embedded GFRP composites. Rheological and FTIR studies confirmed the uniform dispersion of CNCs and chemical bonding between CNC and EP. Rheological studies helped identify the best suitable loadings that approach the practical limit of viscosity required for successful resin infusion. The results demonstrated that CNC-enhanced GFRP composites exhibit significantly improved mechanical properties. Interestingly, a multiscale composite with $2 \mathrm{wt} \%$ of $\mathrm{CNC}$ content, in a glassy state (below $\mathrm{T}_{\mathrm{g}}$ ), yielded a storage modulus(E') which was $56 \%$ higher, a tensile strength which was $24 \%$ higher, a Young's modulus increase of $14 \%$, a flexural modulus $45 \%$ higher and an increase in flexural strength of $55 \%$ over the control GFRP composite. In the rubbery state region (above $\mathrm{T}_{\mathrm{g}}$ at $140^{\circ} \mathrm{C}$ ), the storage modulus of CNC/GFRP composites was also increased significantly by $61 \%, 95 \%$ and $109 \%$, with $0.5,0.1$ and $2.0 \mathrm{wt} \%$ of CNCs compared to the GFRP modulus (2.1 GPa). Moreover, the addition of CNCs to GFRP composites increases the $\mathrm{T}_{\mathrm{g}}$ by $9^{\circ} \mathrm{C}$ (from $91^{\circ} \mathrm{C}$ ) compared to GFRP composites. Fractographic studies revealed that CNCs are strongly imbibed over the glass fibres and well adhered with the thin layer of matrix over fibres. It is expected that the 
presence of the CNCs in the interphase region acted as an effective junction to influence the strengthening of the GFRP interface.

\section{Acknowledgement}

This work was supported by the UK Engineering and Physical Sciences Research Council (EPRSC) grant EP/N007190/1. Dr. Tao Yu is acknowledged for providing help with the rheological studies and Dr. Natalia Plechkova for FTIR studies. Special thanks to Daniel Reid and Jonathan Moffat for assisting with the measurement of mechanical properties.

\section{Conflict of interest:}

The authors declare no competing financial interest

\section{References}

1. Kuttner C, Hanisch A, Schmalz H, Eder M, Schlaad H, Burgert I, Andreas Fery A. (2013) Influence of the Polymeric Interphase Design on the Interfacial Properties of (Fibre-Reinforced) Composites. ACS Appl Mater Inter 2013; 5: 2469-2478

2. Jeyakumar R, Sampath PS,Ramamoorthi, R, Ramakrishnan,T.Structural, morphological and mechanical behaviour of glassfibre reinforced epoxy nanoclay composites. Int J Adv Manuf Technol 2017; 93:527-535

3. Asadi A, Miller M, Moon RJ, Kalaitzidou K. Introducing cellulose nanocrystals in sheet molding compounds (SMC). Compos Part A Appl Sci Manuf 2016; 88: 206215.

4. Yao X, Falzon BG, Hawkins SC.Orthotropic electro-thermal behaviour of highly aligned carbon nanotube web based composites. Compos Sci Technol 2019;170:157164 
5. Liua MY, Zhu HG, Siddiquia NA, Leung CKY, Kim JK. Glass fibres with clay nanocomposite coating: Improved barrier resistance in alkaline environment. Compos Part A Appl Sci Manuf 2011; 42:2051-2059

6. Liu L, Jia C, He J, Zhao F, Fan D, Xing L, Wang M, Wang F, Huang JZ. Interfacial characterization, control and modification of carbon fiber reinforced polymer composites. Compos. Sci. and Technol. 2015; 121: 56-72

7. Eesaee M, Shojaei A. Effect of nanoclays on the mechanical properties and durability of novolac phenolic resin/woven glass fibre composite at various chemical environments, Compos Part A Appl Sci Manuf 2014;63:149-158

8. Wang F, Drzal LT, Qin Y, Huang Z.Size effect of graphene nanoplatelets on the morphology and mechanical behavior of glass fibre/epoxy composites. J Mater Sci 2016; 51:3337-48

9. Menbari S, Ashori A, Rahmani H, Bahrami R. Viscoelastic response and interlaminar delamination resistance of epoxy/glass fibre/functionalized graphene oxide multiscale composites. Polym Test 2016;54:186-195

10. Yuchang Q, Jie W, Hongyu W, Fa L, Wancheng Z. Graphene nanosheets/Eglass/epoxy composites with enhanced mechanical and electromagnetic performance. RSC Adv 2016; 6: 80424

11. Rathore DK,Prusty RK, Kumar DS, Ray BC. Mechanical performance of CNT-filled glass fibre/epoxy composite in in-situ elevated temperature environments emphasizing the role of CNT content. Compos Part A Appl Sci Manuf 2016; 84:364376.

12. Hung PY, Lau KT, Fox B, Hameed N, Lee JH, Hui D. Surface modification of carbon fibre using graphene-related materials for multifunctional composites. Compos Part B-Eng 2016; 133:240-257.

13. Zhu J, Wei S, Ryu J, Budhathoki M, Liangd G, Guo Z. In situ stabilized carbon nanofibre (CNF) reinforced epoxy nanocomposites. Mater Chem 2010; 20: 49374948.

14. Kargarzadeh H, Mariano M, Huang J, Lin N,Ahmad I, Dufresne A, Thomas S. Recent developments on nanocellulose reinforced polymer nanocomposites: A review. Polym 2017; 132:368-393. 
15. Xu S, Girouard N, Schueneman G, Shofner ML, Meredith JC. Mechanical and thermal properties of waterborne epoxy composites containing cellulose nanocrystals. Polym 2013; 54 : 6589-6598.

16. Gabr MH, Elrahman MA, Okubo K, Fujii T. A study on mechanical properties of bacterial cellulose/epoxy reinforced by plain-woven carbon fibre modified with liquid rubber. Compos Part A Appl Sci Manuf 2010; 41:1263-1271.

17. Asadi A, Miller M, Sultana S, Moon RJ, Kalaitzidou K. Introducing cellulose nanocrystals in sheet molding compounds (SMC). Compos Part A Appl Sci Manuf 2016; 88 :206-215

18. Asadi A, Miller M, Moon RJ, Kalaitzidou K. Improving the interfacial and mechanical properties of short glass fibre/epoxy composites by coating the glass fibres with cellulose nanocrystals, eXPRESS Polym Lett 2016;10: 587-597

19. Liu Y, Xiao HM, Feng QP, Fu SY. Synergistic effect of carbon nanotubes and nbutyl glycidyl ether on matrix modification for improvement of tensile performance of glass fibre/epoxy composites. Compos Part A Appl Sci Manuf 2014; 62:39-44.

20. Tian MT, Zhen X, Wang ZW, Zou H, Zhang L, Ning N. Bioderived Rubber-Cellulose Nanocrystal Composites with Tunable Water-Responsive Adaptive Mechanical Behavior. ACS Appl Mater Inter 2017; 9: 6482-6487.

21. Li MC, Wu Q, Song K, Lee S, Qing Y, Wu Y.Cellulose Nanoparticles: Structure-Morphology-Rheology Relationships. ACS Sustainable Chem. Eng 2015;3: 821-832.

22. Nadiv R, Vasilyev G, Shtein M, Peled A, Zussman E, Regev O. The multiple roles of a dispersant in nanocomposite systems. Composites Science and Technology 2016; 133: 192-199.

23. Dorigato A, Morandi S, Pegoretti A. Effect of nanoclay addition on the fibre/matrix adhesion in epoxy/glass composites., J Compos Mater 2011;46:1439-1451.

24. Xu X,Liu F, Jiang L, Zhu JY, Haagenson D, Wiesenborn DP. Cellulose Nanocrystals vs. Cellulose Nanofibrils: A Comparative Study on Their Microstructures and Effects as Polymer Reinforcing Agents. ACS Appl. Mater. Inter 2013;5: 2999-3009

25. Khelifa F, Habibi Y, Bonnaud L, Dubois P. Epoxy Monomers Cured by High Cellulosic Nanocrystal Loading. ACS Appl Mater Inter 2016; 8:10535-10544. 
26. Zhang W, Li X, Yang R. Pyrolysis and fire behaviour of epoxy resin composites based on a phosphorus-containing polyhedral oligomeric silsesquioxane (DOPOPOSS). Polym Degrad Stab 2011; 96: 1821-1832.

27. Gao R, Lu Y, Xiao S, Li J. Facile fabrication of nanofibrillated chitin/Ag2O heterostructured aerogels with high iodine capture efficiency. Sci Rep 2017; 7: 4303.

28. Nuruddin MD, Hosur M, Mahdi T, Jeelani S. Flexural, Viscoelastic and Thermal Properties of Epoxy Polymer Composites Modified with Cellulose Nanofibers Extracted from Wheat Straw. Sensors \& Transducers 2017; 210:1-8.

29. Chen Li, Shengfang Li and Shilin Y. Facile and green preparation of biobased graphene oxide/furan resin nanocomposites with enhanced thermal and mechanical properties. RSC Adv 2016; 6: 62572

30. Gupta S, Rahaman A. Effect of carbon nanotubes on thermos-mechanical properties of glass fibre/epoxy laminated nanocomposites. Int J Sci Res 2015; 5:1-5.

31. Uribe BEB, Chiromito EMS, Carvalho AJF, Tarpani JR. Low-cost, environmentally friendly route for producing CFRP laminates with microfibrillated cellulose interphase. eXPRESS Polymer Letters 2017;11:47-59

32. Kim M, Park YB, Okoli OI, Zhang C. Processing, characterization, and modeling of carbon nanotube-reinforced multiscale composites. Compos. Sci. and Technol 2009; $69: 335-342$

33. Patterson BA, Malakooti MH, Lin J, Okoromd A, Sodano HA. Aramid nanofibers for multiscale fiber reinforcement of polymer composites. Compos. Sci. and Technol 2018;161:92-99

34. Zanjani JSM, Okan BS, Menceloglu YZ, Yildiz M. Nano-engineered design and manufacturing of high performance epoxy matrix composites with carbon fiber/selectively integrated graphene as multi-scale reinforcements. RSC Adv. 2016; 6: 9495

35. Zhang X, Fan X, Yan C, Li H, Zhu Y, Li X, and Yu L. Interfacial Microstructure and Properties of Carbon Fiber Composites Modified with Graphene Oxide. ACS Appl. Mater. Interfaces 2012; 4: 1543-1552

36. Halder S, Ahemad S,Da S, and Wang J. Epoxy/Glass Fiber Laminated Composites Integrated with Amino Functionalized $\mathrm{ZrO} 2$ for Advanced Structural Applications. ACS Appl Mater Interfaces 2016; 8: 1695-1706

37. Liao WH, Tien HW, Hsiao ST, Li SM, Wang YS, Huang YL, Yang SY, Ma CCM, $\mathrm{Wu}$ YF.,Effects of Multiwalled Carbon Nanotubes Functionalization on the 
Morphology and Mechanical and Thermal Properties of Carbon Fibre/Vinyl Ester Composites. ACS Appl. Mater. Inter 2013;5: 3975-3982.

38. Goswami J, Haque E, Fox DM,Gilman JW, Holmes GA, Moon RJ and Kalaitzidou K.The Effect of Cellulose Nanocrystal Coatings on the Glass Fiber-Epoxy Interphase. Materials 2019; 12: 1951

39. Adak NC, Chhetri S, Murmu NC, Samanta P, Kuila T, Lee JH.Experimental and numerical investigation on the mechanical characteristics of polyethylenimine functionalized graphene oxide incorporated wovencarbon fibre/epoxy composites. Composites Part B 2019; 156: 240-251.

40. Siqueira G, Mathew AP, Oksman K, Processing of cellulose nanowhiskers/cellulose acetate butyrate nanocomposites using sol-gel process to facilitate dispersion. Composites Science and Technology 2011; 71: 1886-1892

41. Uribe BEB, Chiromito EMS, Carvalho AJF, Arenal R, Tarpani JR. TEMPO-oxidized cellulose nanofibers as interfacial strengthener in continuous-fiber reinforced polymer composites. Materials and Design 2017; 133: 340-348.

42. Jyoti J, Babal AS, Sharma S,Dhakate SR, Singh BP.Significant improvement in static and dynamic mechanical properties of graphene oxide-carbon nanotube acrylonitrile butadiene styrene hybrid composites. J Mater Sci 2018; 53:2520-2536.

43. Zhao F, Huang Y, Liu L, Bai Y, Xu. Formation of a carbon fiber/polyhedral oligomeric silsesquioxane/carbon nanotube hybrid reinforcement and its effect on the interfacial properties of carbon fiber/epoxy composites. Carbon 2011; 49:2624-2632

44. Kumar S, Hofmann M, Steinmann B, Foster EJ, Weder C. Reinforcement of Stereolithographic Resins for Rapid Prototyping with Cellulose Nanocrystals. ACS Appl. Mater. Interfaces 2012; 10: 5399-5407

45. Shanhong Xu, Girouard N, Schueneman G, Shofner ML, Meredith JC. Mechanical and thermal properties of waterborne epoxy composites containing cellulose nanocrystals.Polymer 2013; 54 6589-6598

46. Tehrani M,Boroujeni A.Y ,Hartman TB, Haugh TP,Case SW,AlHaik MS. Mechanical characterization and impact damage assessment of a woven carbon fibre reinforced carbon nanotube-epoxy composite. Compos Sci and Technol 2017;75: 42-48

47. Varma AJ, Jamdade YK, Nadkarni VM. Curing characteristics of epoxy resins filled with cellulose and oxidized cellulose. Angew Makromol Chem 1984; 122:211-8. 
48. Cheni Y, Zhou X, Yin X, Lin Q, Zhy M. A Novel Route to Modify the Interface of Glass Fibre-Reinforced Epoxy Resin Composite via Bacterial Cellulose. Int J Polym Mater Polym Biomater 2014; 63: 221-227. 


\section{FIGURES}
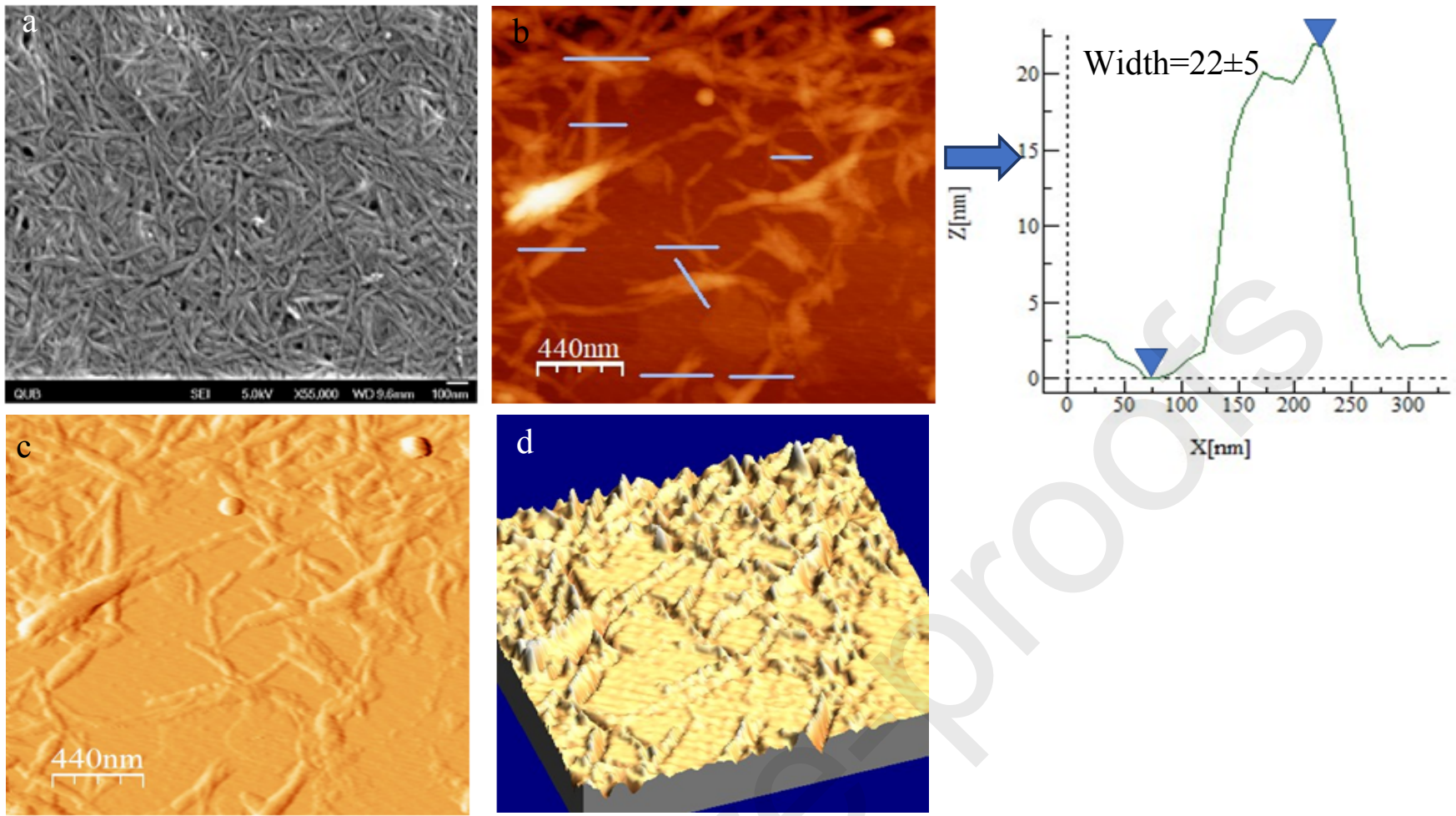

$\mathrm{X}[\mathrm{nm}]$

Figure1. (a) SEM image of as-received freeze-dried CNCs and (b-d) representative AFM images of CNCs; (b) topographical and height profile (c) amplitude (d) 3D image. AFM images obtained from dispersion (conc. $1.0 \mathrm{mg} / \mathrm{ml}$ (deionized-water)) onto a silicon wafer

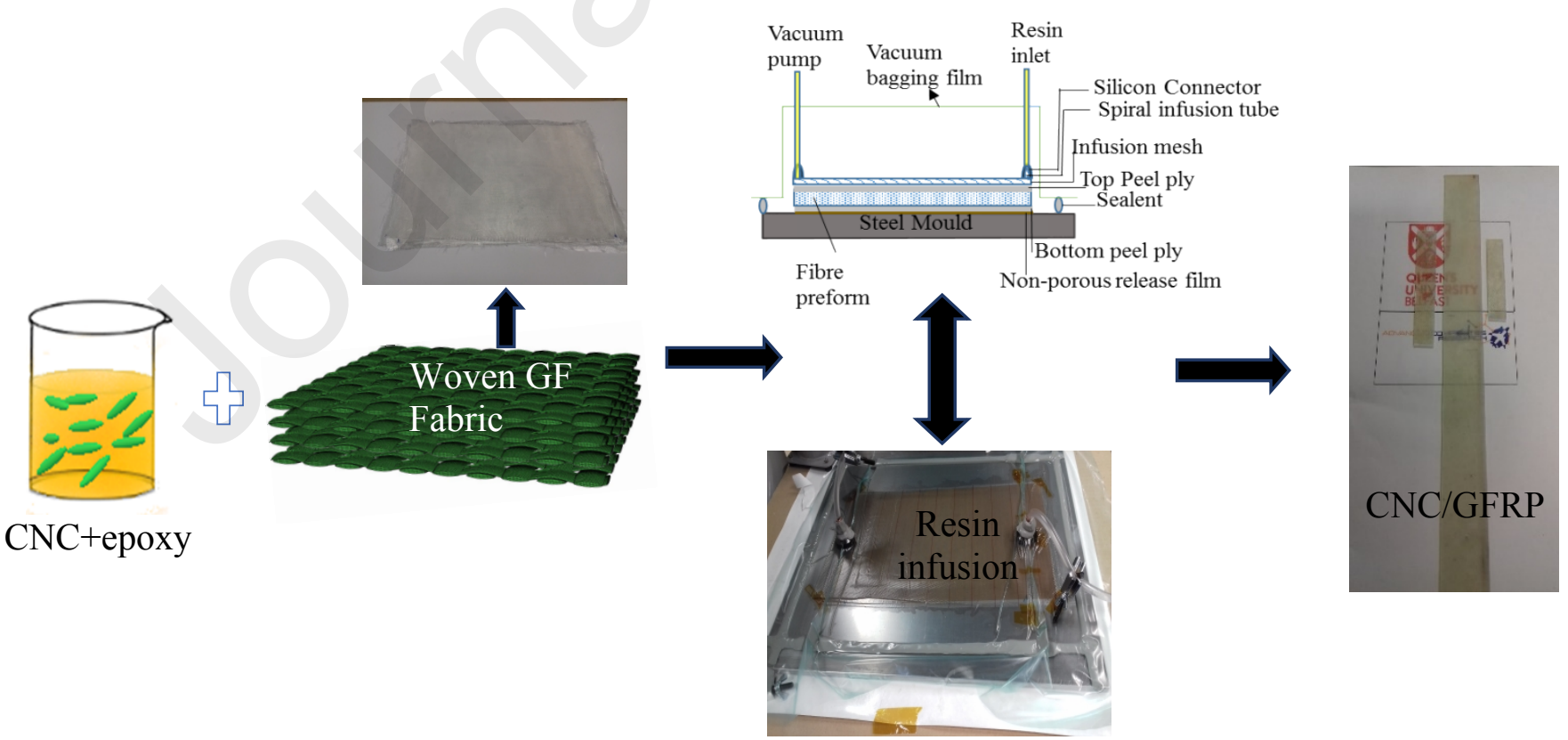

Figure 2. (a) Schematic representation of CNC/GFRP composites manufacturing process. 

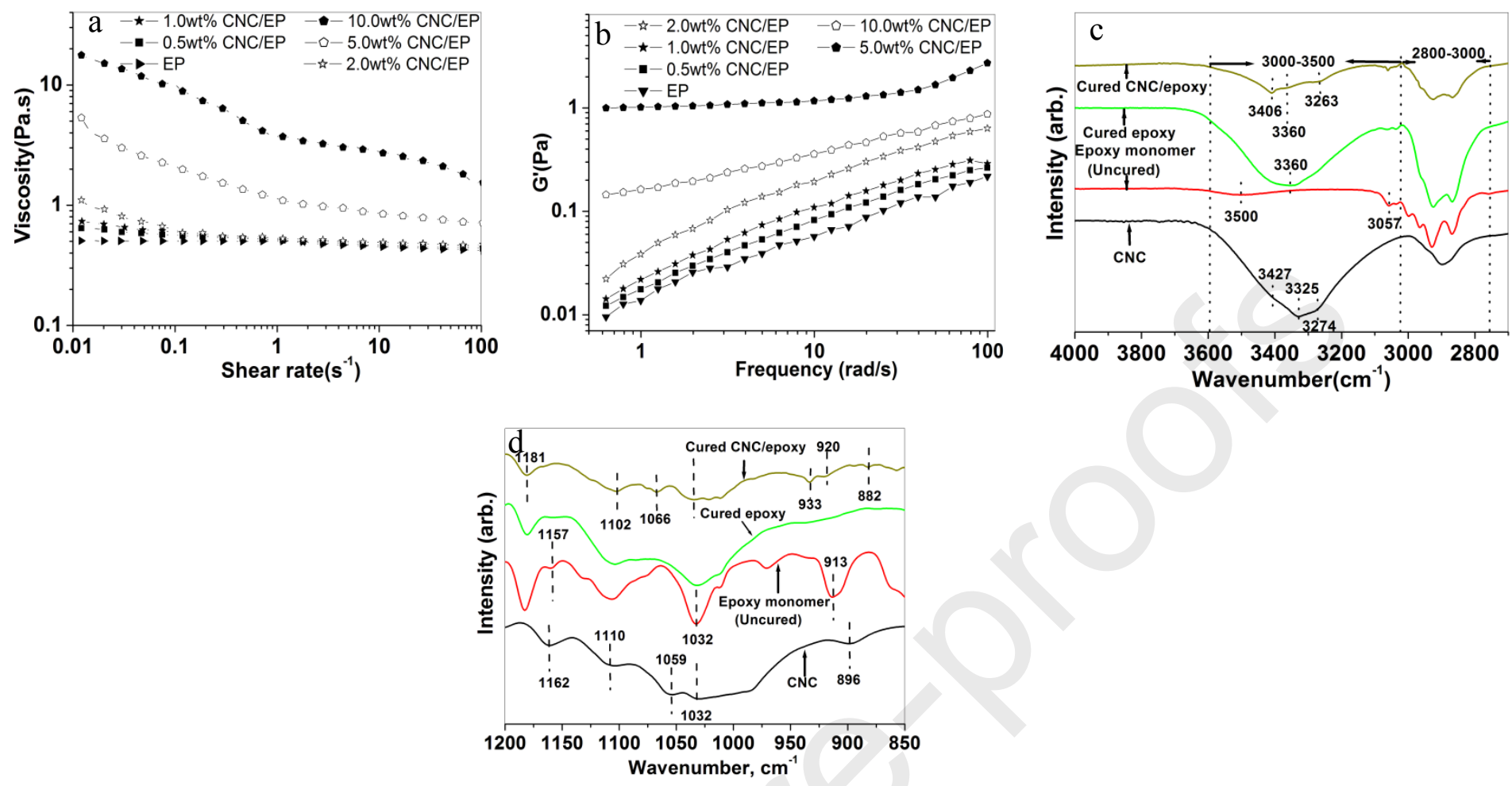

Figure 3. (a) Viscosity vs shear rate (b) storage modulus ( $\left.G^{\prime}\right)$ vs frequency of uncured-CNC/EP mixtures, (c-d) FTIR spectra of CNC, EP monomer, cured EP and CNC/EP composite.
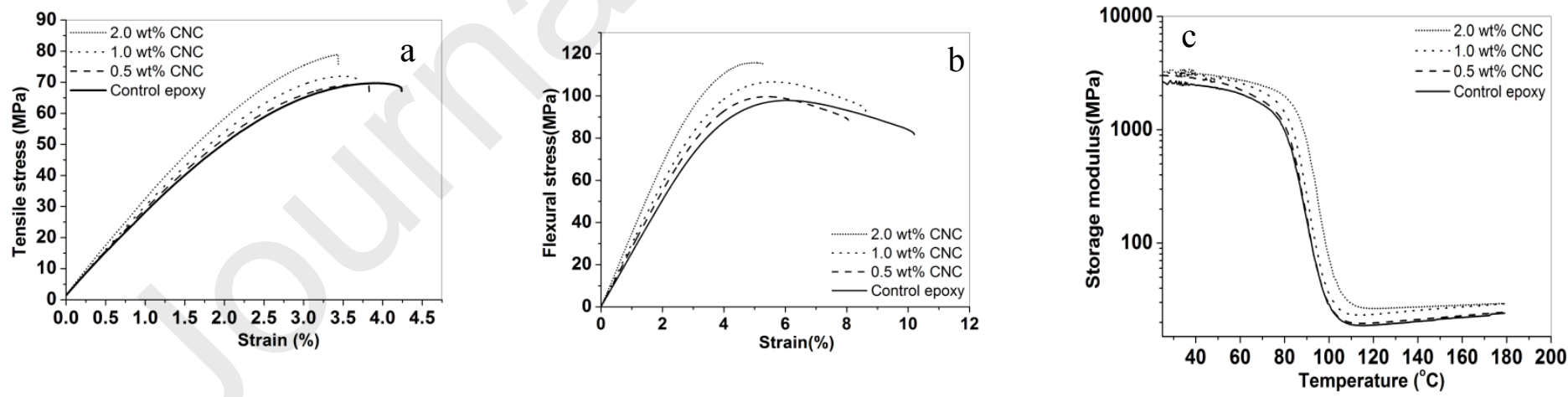

Fig.4: (a) Tensile stress vs strain (b) flexural stress vs strain (c) storage modulus of CNC/EP composites 


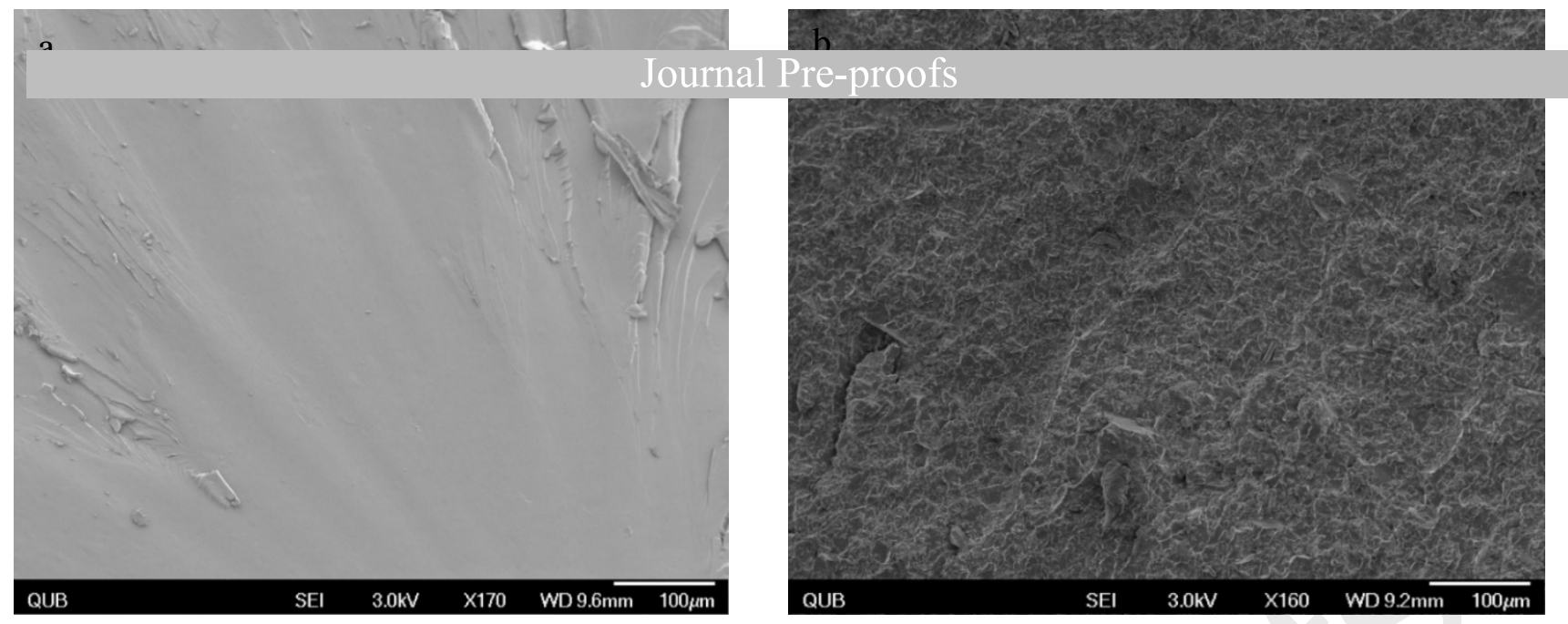

Figure 5. Morphological study of tensile fractures surface of (a) control epoxy and (b) 2.0 wt $\%$ CNC/epoxv composite.
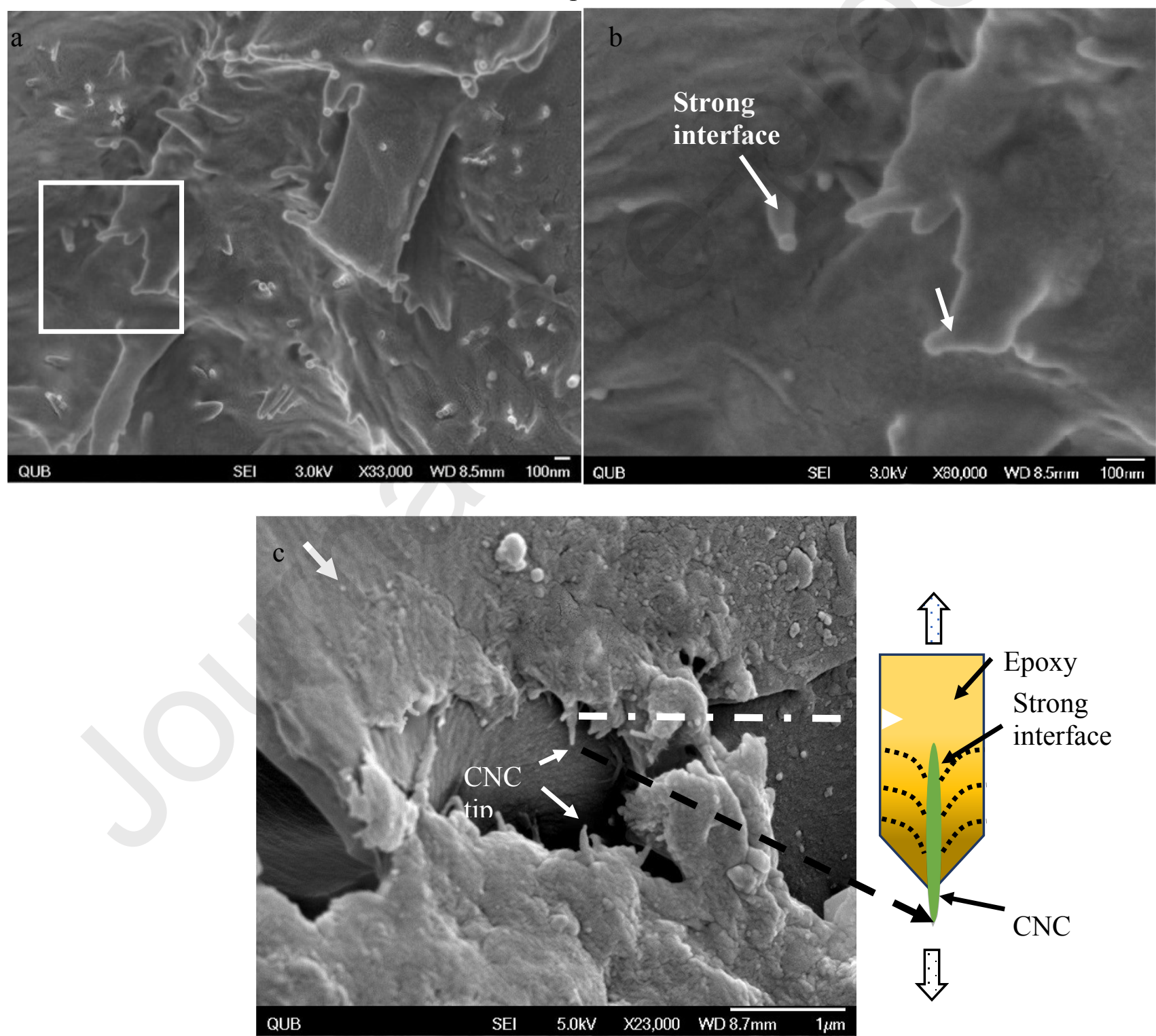

Figure 6: Morphological study of tensile fractures surface of $2.0 \mathrm{wt} \% \mathrm{CNC} / \mathrm{epoxy}$ composite 


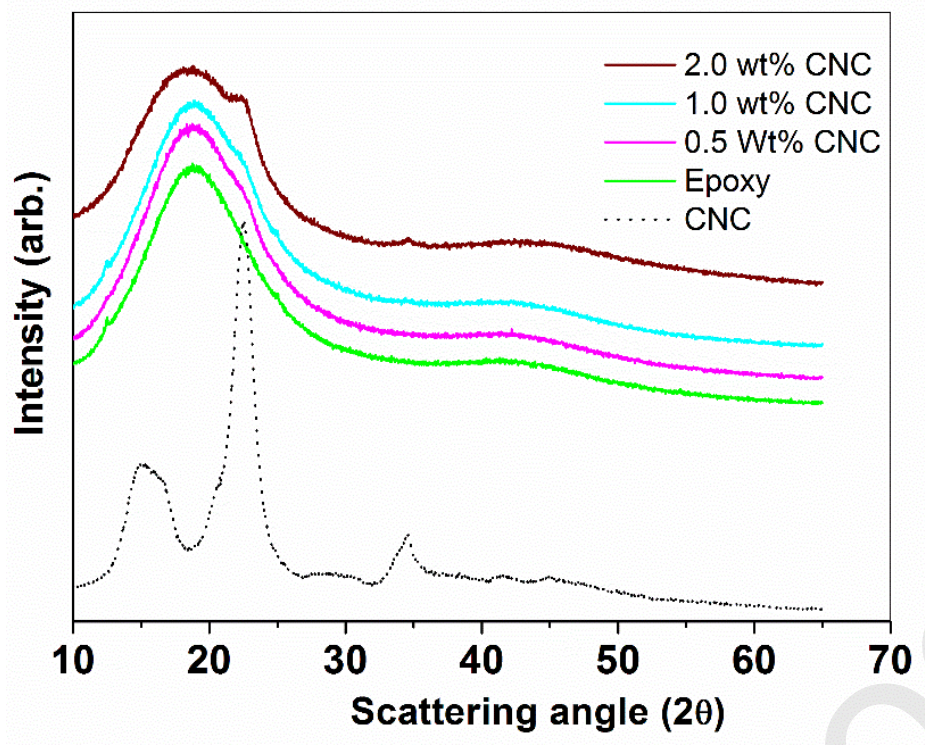

Figure 7: XRD study of CNC/epoxy composites
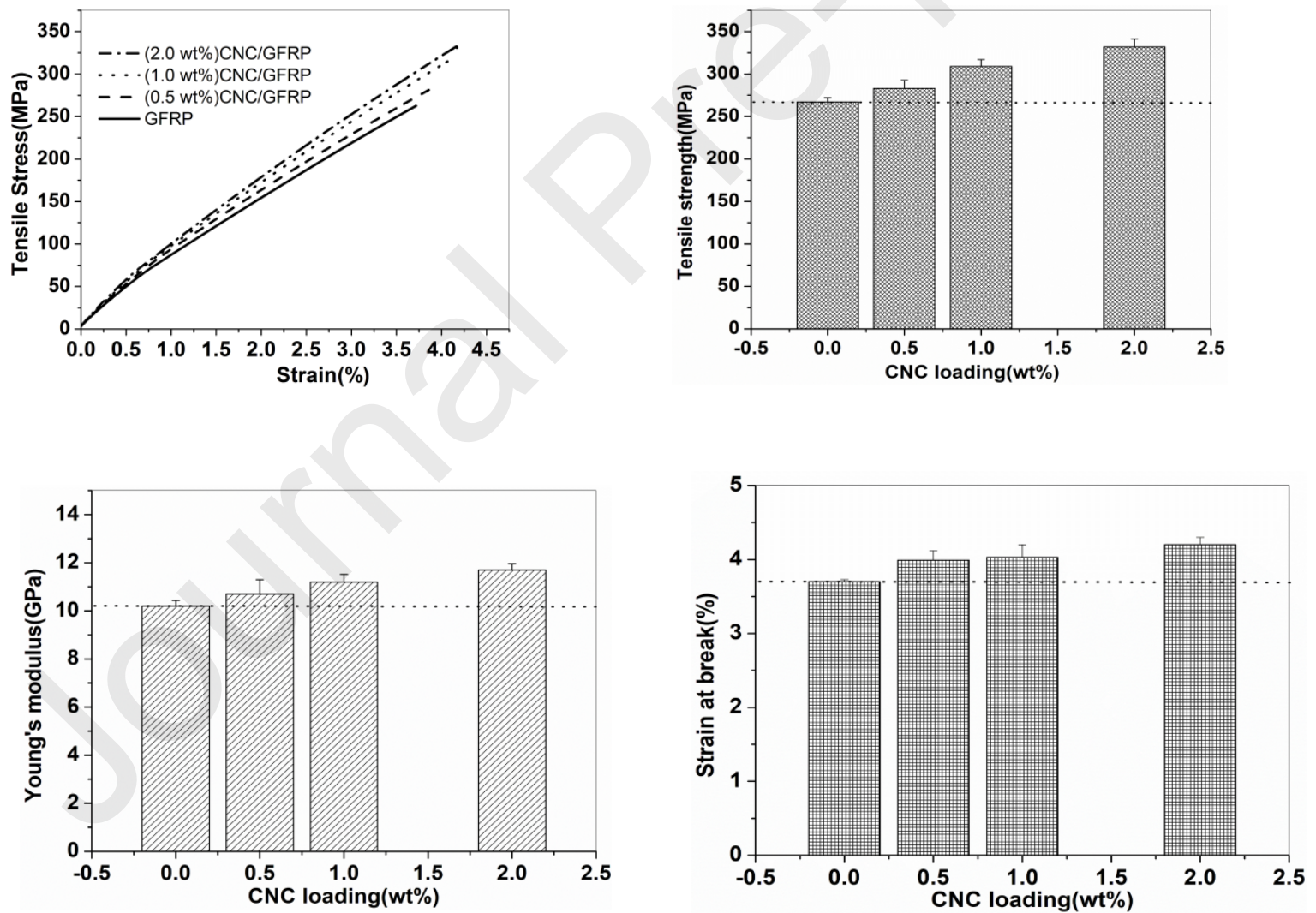

Figure 8: Tensile properties of GFRP and CNC/GFRP composites 

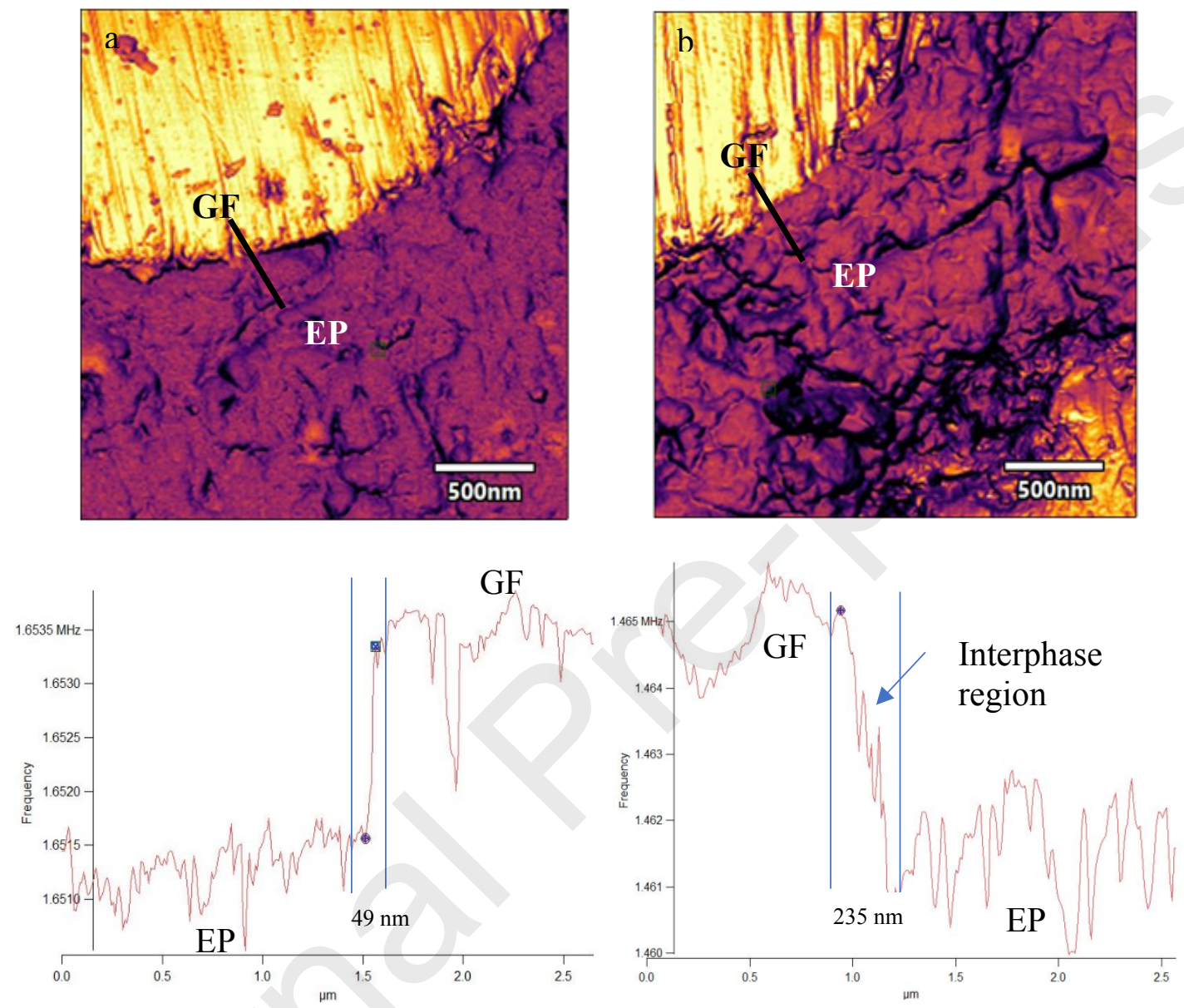

Figure 9: AM-FM viscoelastic mapping images of composite interfaces (a) GFRP and (b) 2.0 wt $\%$ CNC/GFRP with line profiles. The diagonal black line starting over the fibre surface, crossing the interphase region and ending over the EP matrix surface. The transitions between dots corresponds to the interphase region. 

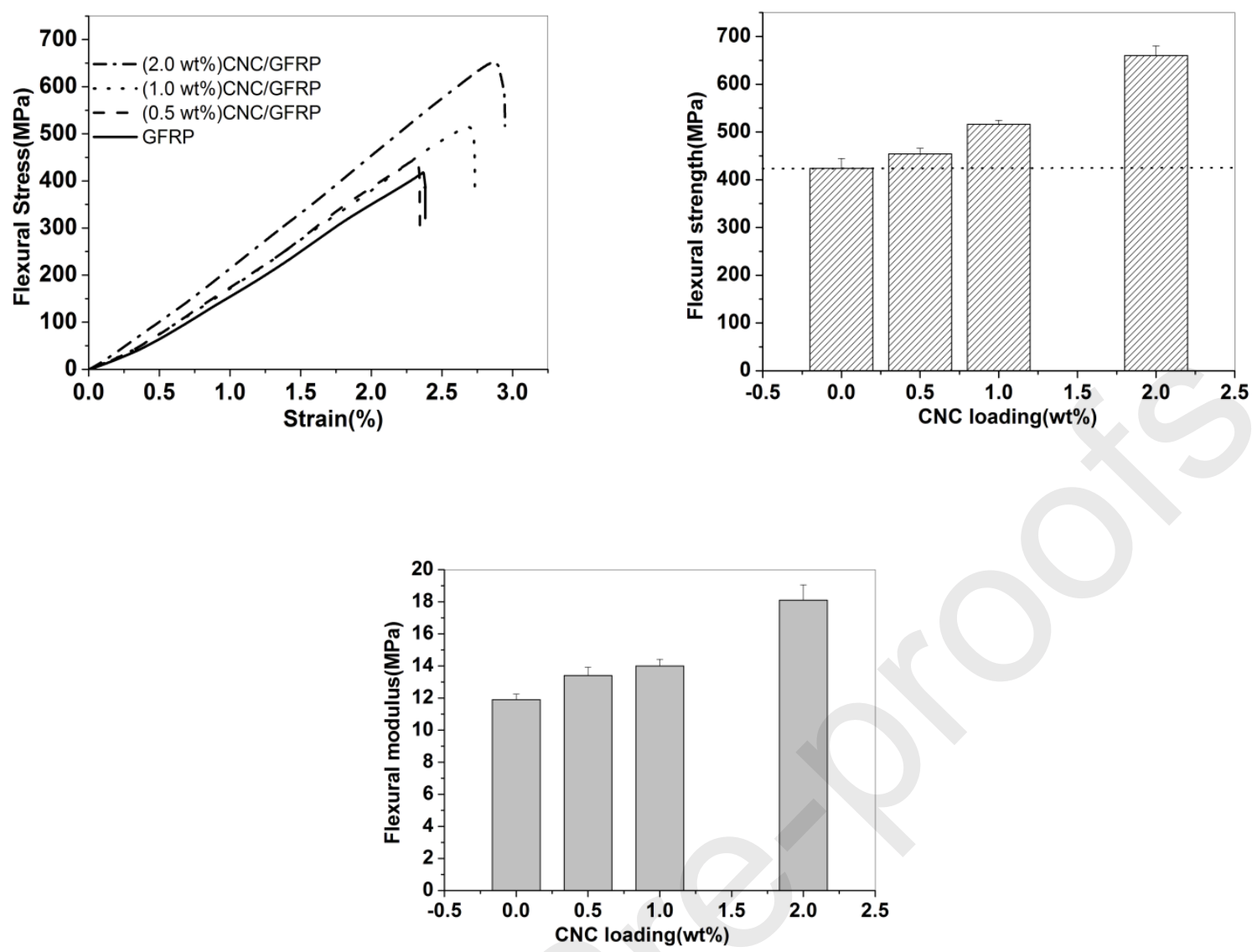

Figure 10: Flexural properties of GFRP and CNC/GFRP composites
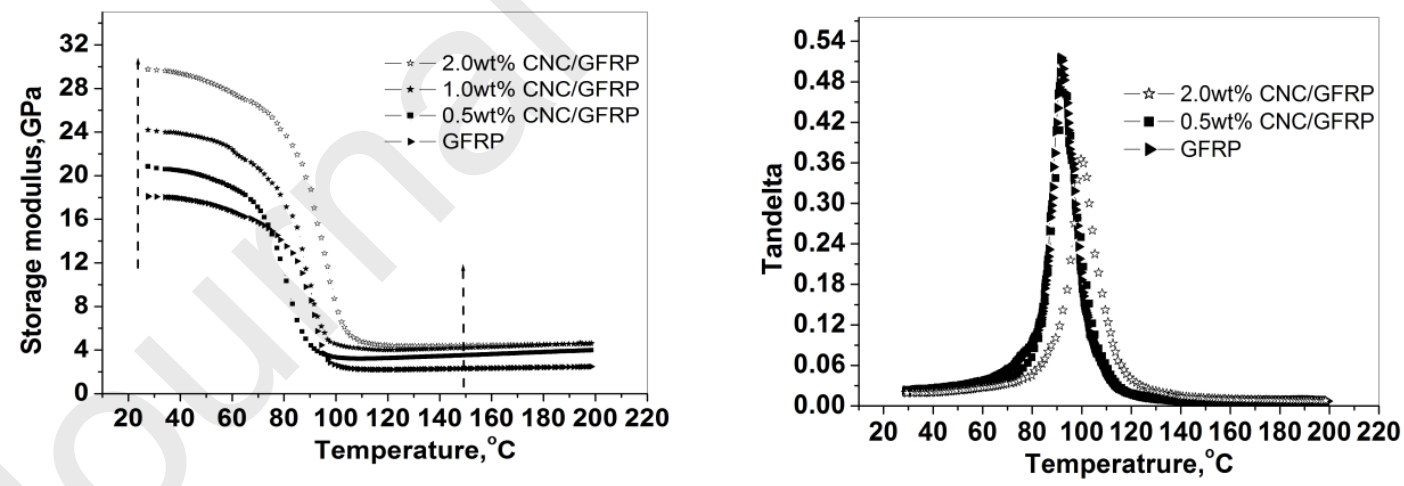

Figure 11: Storage modulus and Tandelta spectra of GFRP and CNC/GFRP composites 


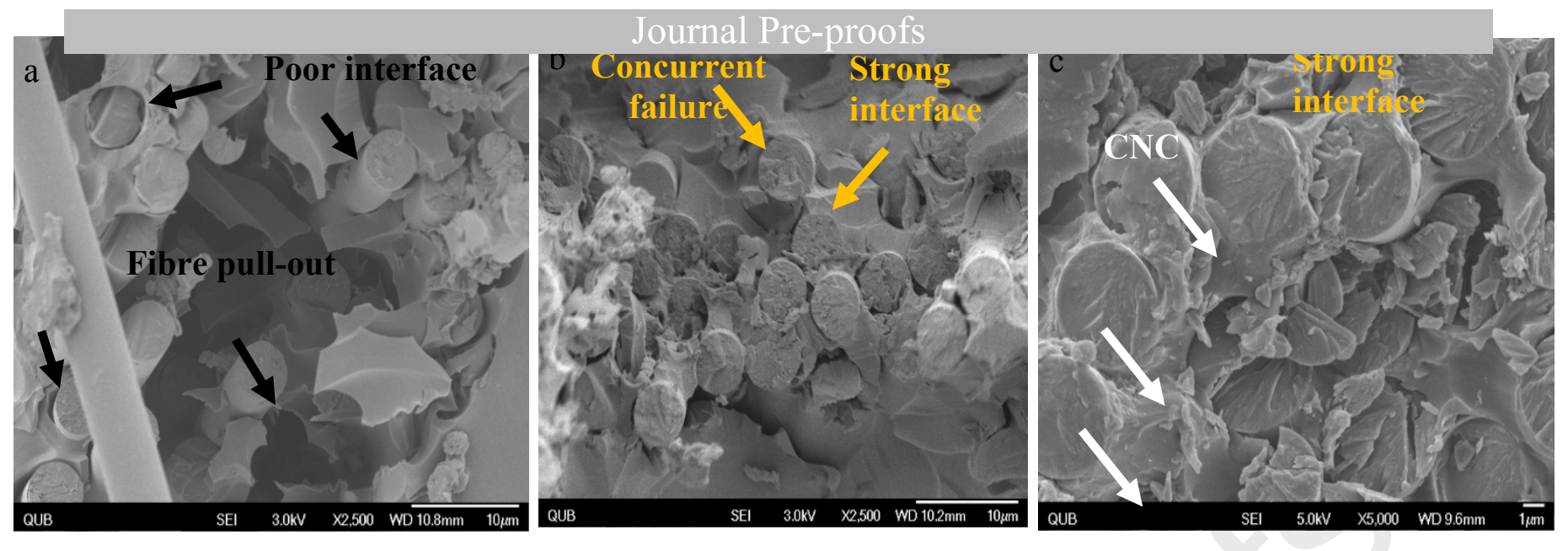

Figure 12: (a) SEM image of tensile fractured surface of GFRP composite, (b\&c) $2.0 \mathrm{wt} \%$

CNC/GFRP composite.
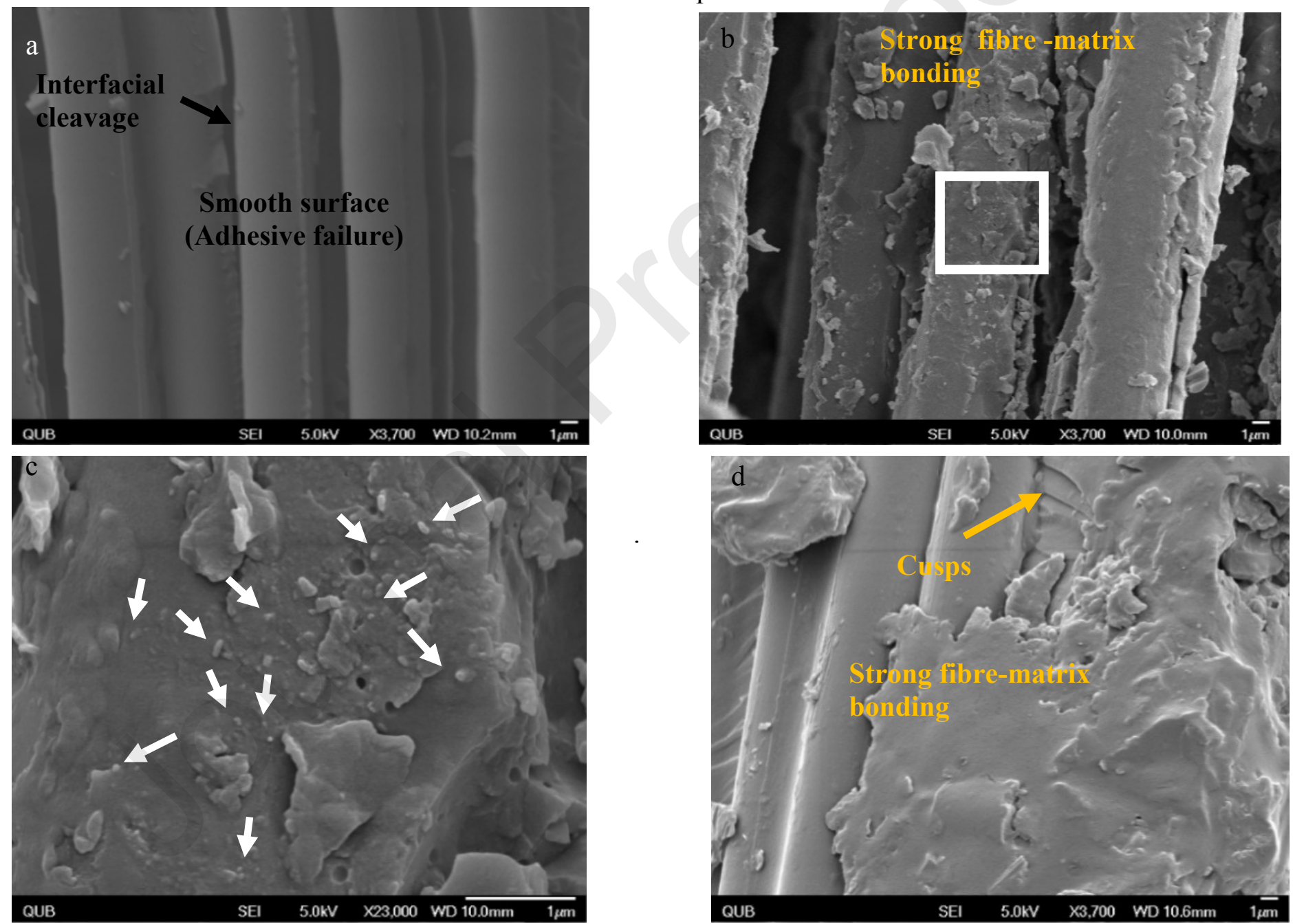

Figure 13: SEM images of tensile fractured surface of (a) GFRP and (b-c) $2.0 \mathrm{wt} \%$

$\mathrm{CNC/GFRP} \mathrm{composite.} \mathrm{Image} \mathrm{(c)} \mathrm{is} \mathrm{the} \mathrm{magnified} \mathrm{version} \mathrm{of} \mathrm{image} \mathrm{(b,} \mathrm{white} \mathrm{square)}$ 


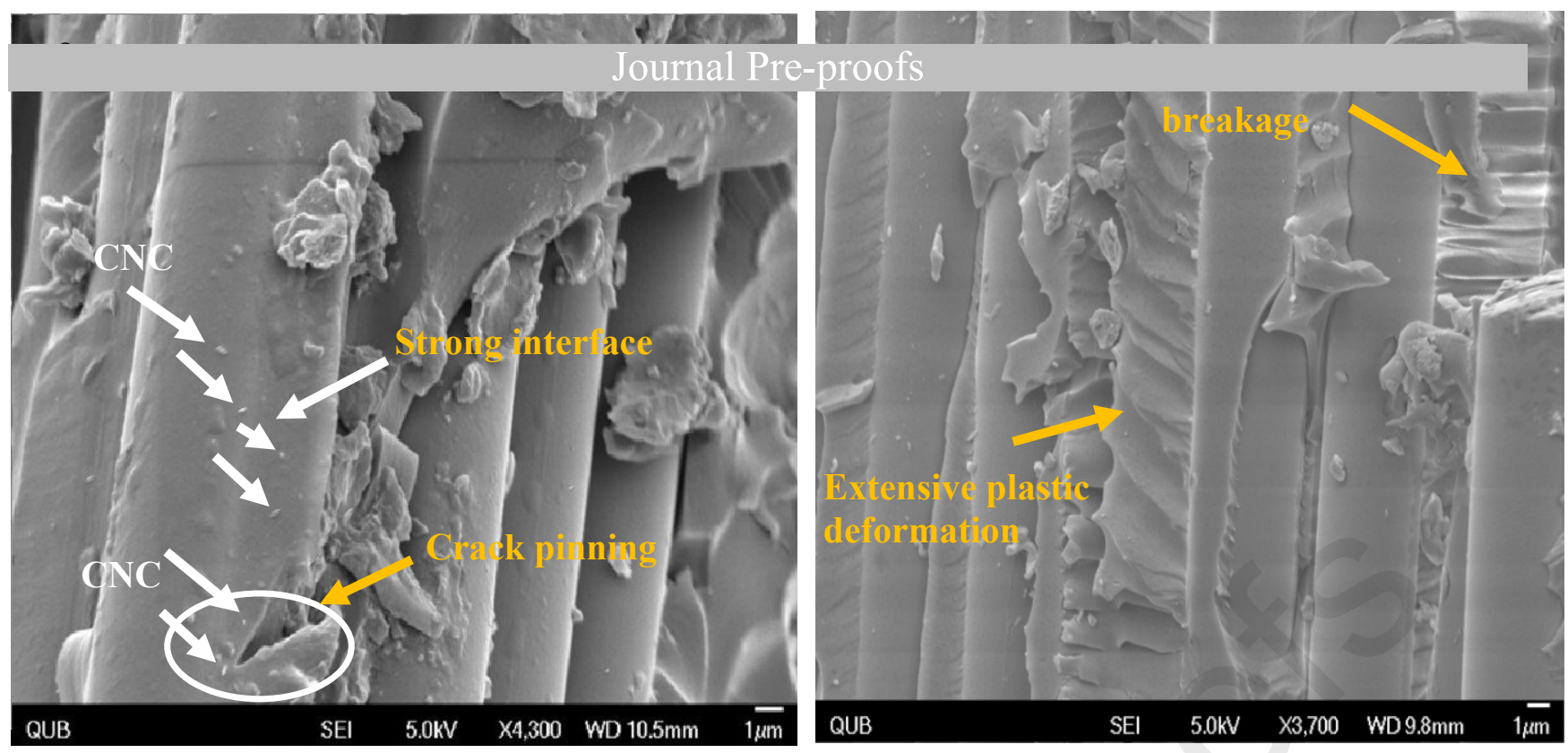

Figure 14 (a-b): SEM images of tensile fractured surface of $2.0 \mathrm{wt} \% \mathrm{CNC} / \mathrm{GFR}^{\mathrm{P}}$ composite.
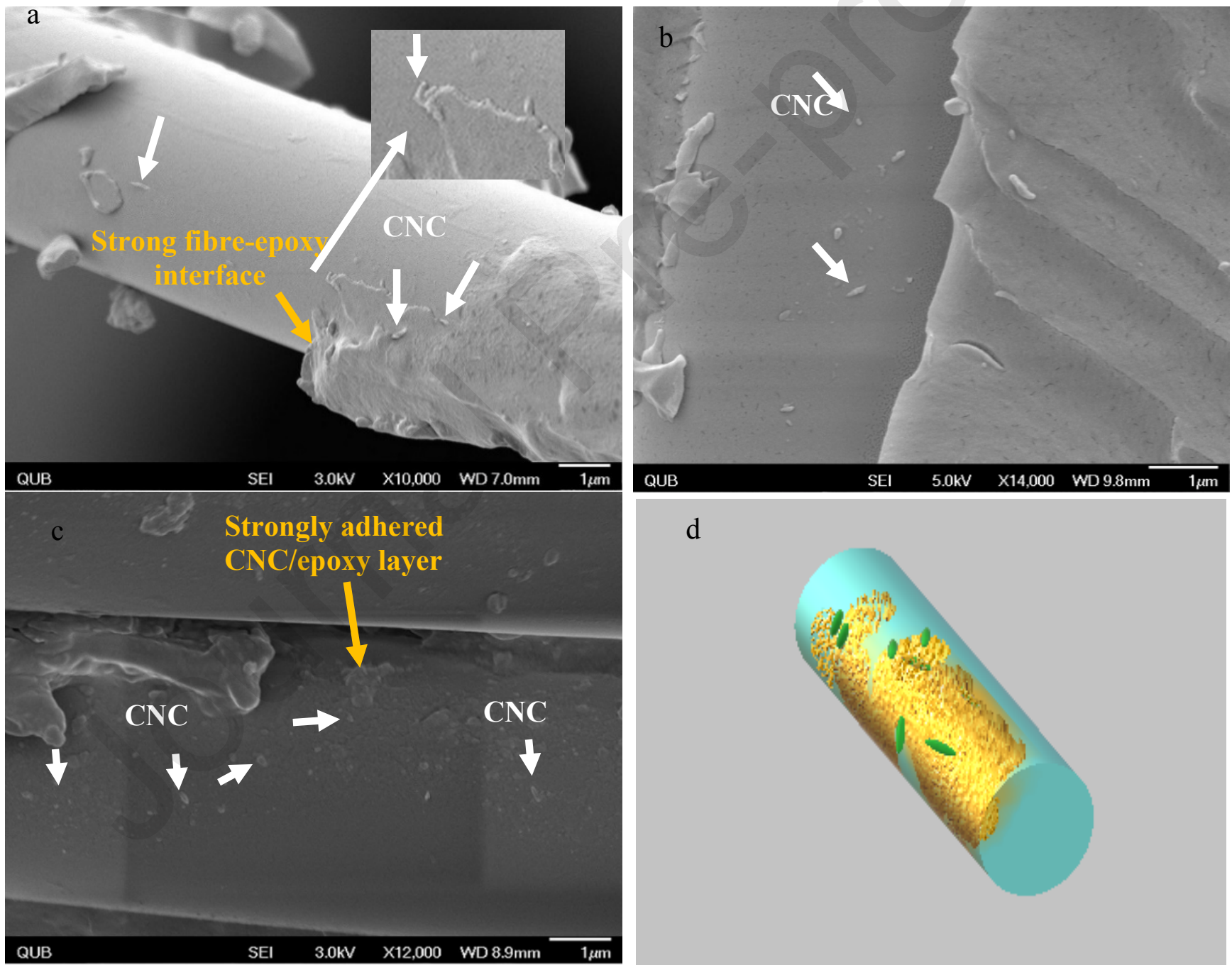

Figure 15: (a-c) High magnification SEM fractured surface images of 2.0wt $\%$ CNC/GFRP composite and (d) 3-D representation showing CNC/epoxy attachment over the fibre surface. 
Table 1 Mechanical properties of GFRP and CNC/GFRP composites.

\begin{tabular}{|c|c|c|c|c|c|}
\hline $\begin{array}{c}\text { Composite } \\
\text { systems }\end{array}$ & $\begin{array}{c}\text { Flexural } \\
\text { modulus } \\
(\mathrm{GPa})\end{array}$ & $\begin{array}{c}\text { Flexural } \\
\text { strength } \\
(\mathrm{MPa})\end{array}$ & $\begin{array}{c}\text { Tensile strength } \\
\left(\sigma_{\mathrm{ts}}\right)\end{array}$ & $\begin{array}{c}\text { Young's } \\
\text { Modulus } \\
(\mathrm{E}) \\
(\mathrm{GPa}) \\
\mathrm{MPa}\end{array}$ & $\varepsilon(\%)$ \\
\hline GFRP & $11.9 \pm 0.35$ & $424 \pm 20.6$ & $267 \pm 5.2$ & $10.2 \pm 0.23$ & $3.7 \pm 0.03$ \\
\hline $\begin{array}{c}0.5 \mathrm{wt} \% \\
\mathrm{CNC} / \mathrm{GFRP}\end{array}$ & $13.4 \pm 0.52$ & $454 \pm 10.4$ & $283 \pm 9.8$ & $10.7 \pm 0.6$ & $3.99 \pm .13$ \\
\hline $\begin{array}{c}1.0 \mathrm{wt} \% \\
\mathrm{CNC} / \mathrm{GFRP}\end{array}$ & $14.0 \pm 0.41$ & $516 \pm 8.3$ & $309 \pm 7.9$ & $11.2 \pm .32$ & $4.03 \pm 0.17$ \\
\hline $\begin{array}{c}2.0 \mathrm{wt} \% \\
\mathrm{CNC} / \mathrm{GFRP}\end{array}$ & $18.1 \pm 0.95$ & $660 \pm 20.09$ & $332 \pm 9.2$ & $11.7 \pm 0.26$ & $4.2 \pm 0.10$ \\
\hline
\end{tabular}

Table 2 Mechanical properties improvement comparison of CNC/GFRP and different types of nanofiller/GFRP composites.

\begin{tabular}{|c|c|c|c|c|c|c|c|}
\hline $\begin{array}{l}\text { Composite } \\
\text { systems }\end{array}$ & $\begin{array}{l}\text { Nano } \\
\text { fillers } \\
(\mathrm{wt} \%)\end{array}$ & $\begin{array}{c}\text { Storage } \\
\text { modulus } \\
\left(\mathrm{E}^{\prime}\right) \\
(\%)\end{array}$ & $\begin{array}{c}\text { Flexural } \\
\text { modulus } \\
(\%)\end{array}$ & $\begin{array}{l}\sigma_{\mathrm{ts}} \\
(\%)\end{array}$ & $\begin{array}{c}\text { Young's } \\
\text { Modulus } \\
\text { (E) } \\
(\%)\end{array}$ & $\begin{array}{c}\text { Flexural } \\
\text { Strength } \\
(\%)\end{array}$ & Ref. \\
\hline Clay/GFRP & 5.0 & ----- & 53 & 23.5 & 23.6 & 34 & 2 \\
\hline $\mathrm{CB}^{*} / \mathrm{GFRP}$ & 2.5 & 17 & 15 & 14 & 43 & 6.7 & 7 \\
\hline GNP*/GFRP & 5.0 & 28 & 26 & ---- & $\begin{array}{ll}---- \\
--\end{array}$ & 16 & 8 \\
\hline F-G*/GFRP & 0.5 & 42 & & 20 & 33 & $\begin{array}{ll}---- \\
\end{array}$ & 9 \\
\hline Graphene/GFRP & 2.0 & --- & 58.4 & ----- & ----- & 78.8 & 10 \\
\hline $\begin{array}{c}\text { F- } \\
\text { MWNTs*/GFRP }\end{array}$ & $\begin{array}{l}0.1 \\
0.5\end{array}$ & $\begin{array}{c}4 \\
16\end{array}$ & $\begin{array}{c}11 \\
9\end{array}$ & $\begin{array}{ll}---- \\
\end{array}$ & $\begin{array}{ll}---- \\
\end{array}$ & $\begin{array}{l}32 \\
15\end{array}$ & 11 \\
\hline MWNTs/GFRP & 0.5 & ----- & & 28 & 14.9 & ----- & 19 \\
\hline MWNTs/GFRP & 1.0 & 38 & $-\overline{---}$ & 21 & 32 & ----- & 28 \\
\hline CNC/GFRP & 2.0 & 56 & 50 & 20 & 20 & 55 & $\begin{array}{l}\text { This } \\
\text { work }\end{array}$ \\
\hline
\end{tabular}

F-G: Functionalized graphene; F-MWNTs: Functionalized multiwalled carbon nanotubes; GO: Graphene oxide; GNP: Graphene nanopatelets; CB: Organically modified montmorilonite clay 